\title{
2 Microdevices for extensional rheometry of low viscosity 3 elastic liquids: a review
}

4

\author{
F. J. Galindo-Rosales • M. A. Alves • \\ M. S. N. Oliveira
}

Received: 15 March 2012/ Accepted: 27 June 2012

(C) Springer-Verlag 2012

\begin{abstract}
Extensional flows and the underlying stability/ instability mechanisms are of extreme relevance to the efficient operation of inkjet printing, coating processes and drug delivery systems, as well as for the generation of micro droplets. The development of an extensional rheometer to characterize the extensional properties of low viscosity fluids has therefore stimulated great interest of researchers, particularly in the last decade. Microfluidics has proven to be an extraordinary working platform and different configurations of potential extensional microrheometers have been proposed. In this review, we present an overview of several successful designs, together with a critical assessment of their capabilities and limitations.
\end{abstract}

\section{Keywords Extensional flow · Filament stretching ·}

Filament thinning · Diluted polymer solution · Rheometry · Microfluidics - Extensional viscosity · Viscoelasticity

\section{Introduction}

Extensional deformation plays a significant role in many processing operations of polymer melts and solutions. Examples include extrusion, coating flows, contraction flows, fiber spinning, blow molding, film blowing, and foam

F. J. Galindo-Rosales $(\bowtie) \cdot$ M. A. Alves

Departamento de Engenharia Química, Centro de Estudos de Fenómenos de Transporte (CEFT), Faculdade de Engenharia da Universidade do Porto, Rua Dr. Roberto Frias s/n, 4200-465 Porto, Portugal

e-mail: galindo@fe.up.pt; curro@galindorosales.com

\section{S. N. Oliveira}

Department of Mechanical and Aerospace Engineering, University of Strathclyde, Glasgow G1 1XJ, UK production (Gaudet and McKinley 1998; Zheng et al. 2011). Since extensional flows strongly orient polymer molecules and asymmetric particles, the presence of regions of strong extensional flow in processing operations can have a major effect on final product properties (Macosko 1994). Moreover, in the food industry, the extensional properties are also important in various stages of the product life cycle, from the initial stage of formulation and process design, to process and quality control of products, to the final stage of sensory perception of the product by the consumer (Padmanabhan and Bhattacharya 1993; Padmanabhan 1995; Funami 2011). There are also other industrial and commercial applications, such as agrochemical spraying, inkjet printing, turbulent drag reduction or enhanced oil recovery, in which the extensional properties of the working fluids are of extreme importance (Oliveira et al. 2006; Rothstein 2008), since viscoelastic fluids frequently exhibit strong extensional thickening well beyond the Trouton ratio (Trouton 1906) found for Newtonian fluids $\left(\operatorname{Tr}=\eta_{e} / \eta=3\right.$ for axisymmetric elongation, or $\operatorname{Tr}=\eta_{e} / \eta=4$ for planar elongation). Therefore, in order to accurately model these materials, detect subtle dissimilarities in their composition, and to describe or predict the processing conditions that will optimize fluid flow or characteristics of the final product, a thorough rheological characterization of materials in both shear and extensional flow conditions is recommended (Barnes et al. 1993).

Despite the recognized importance of extensional flows, we still face an unbalanced scenario in the field of rheometry, with the rheological characterization under simple shear flow being by far the most abundant in rheology, to such an extent that it often becomes a synonym for rheology in general (Dukhin and Zelenev 2010). However, it is not possible to describe adequately the highly complex dependency on both strain and strain rate experienced by a

\begin{tabular}{|l|lll|}
\hline & Journal : Large 10404 & Dispatch : 23-7-2012 & Pages : 19 \\
Article No. : 1028 & $\square$ LE & $\square$ TYPESET \\
MS Code : & $\sim_{\mathrm{CP}}$ & $\checkmark_{\text {DISK }}$ \\
\hline
\end{tabular}


fluid element of a viscoelastic material in a strong extensional flow using exclusively a shear rheological characterization. This has been the motivation which has been fueling extensive research in the past decades to understand the extensional flow behavior of different materials. Research in this topic has involved a synergistic effort in theoretical analysis of extensional flow behavior in order to determine the critical parameters and identify the optimal flow kinematics, and in improving the experimental design of extensional rheometers in order to successfully impose the desired kinematics (Nijenhuis et al. 2007). Ideally, a pure extensional (or shear-free) flow, in which the rate-ofstrain tensor $\left(\boldsymbol{D}=\frac{1}{2}\left[\nabla \boldsymbol{v}+\nabla \boldsymbol{v}^{\mathrm{T}}\right]\right)$ has only non-zero values on the diagonal elements $\left(\frac{\partial u_{i}}{\partial x_{j}}=0, \forall i \neq j\right)$ and consequently the vorticity tensor is null $\left(\boldsymbol{w}=\frac{1}{2}\left[\nabla \boldsymbol{v}-\nabla \boldsymbol{v}^{\mathrm{T}}\right]=\mathbf{0}\right)$, would allow us to characterize properly the extensional properties of the fluid. However, due to difficulties associated with imposing purely extensional deformations, the development of instrumentation able to carry out extensional viscosity measurements is still a challenging task. Twenty five years ago, Bird et al. (1987) summarized this idea in the following statement: "Unlike the situation for shear flows where there are numerous methods available for measuring material functions of a wide variety of polymeric liquids, techniques for measuring the kinds of shear-free flow material functions have been developed only for polymer melts and high-viscosity solutions". In spite of the difficulties in generating homogeneous extensional flows, avoiding shear components and controlling the strain history of the material elements (Petrie 1997; Anna et al.
2001; Ríos et al. 2002; Bänsch et al. 2004), especially with low viscosity liquids, significant improvements have been achieved over the last 25 years. As a consequence of this active research, a family of extensional rheometers and detachable extensional rheometer fixtures for use in commercial torsional rheometers are nowadays available on the market and allow the user to cover a wide range of materials from low to highly viscous fluids, and from polymer solutions to polymer melts, as schematically illustrated in Fig. 1. Most of the apparatus developed for measuring the extensional viscosity are more appropriate for high-viscosity materials, such as polymer melts (Münsted 1979; Meissner 1985a, b; Maia et al. 1999; Schweizer 2000; Sentmanat et al. 2005; Göttfert 2011; Franck 2011), mainly due to the fact that the high viscosity of such polymer melts allows the preparation of homogeneous sheets or rods of material that are subsequently subjected to an elongation process under conditions of either constant deformation rate or constant stress (McKinley and Sridhar 2002). On the other hand, methods for determining the extensional properties of less viscous complex fluids, such as dilute polymer solutions, are more limited and in most cases are still under active development.

The opposed jet rheometer developed by Fuller et al. (1987), commercialized as the RFX instrument by Rheometrics (now TA Instruments), was able to characterize the extensional properties of low viscosity fluids. This technique was used extensively to measure the extensional properties of various aqueous solutions in the 1990s (e.g. Hermansky and Boger 1995; $\mathrm{Ng}$ et al. 1996). However, since large deformation rates were required to induce

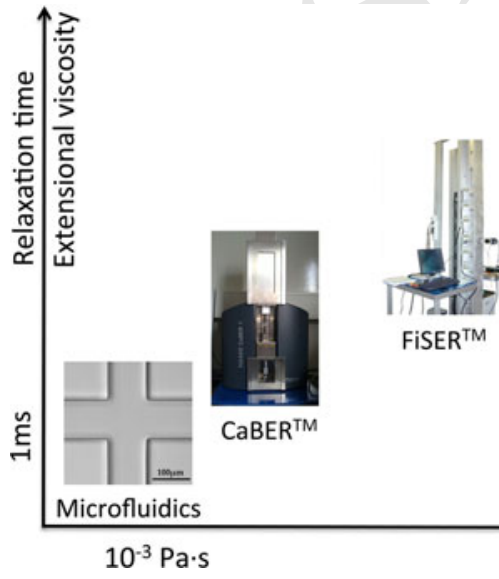

Fig. 1 Range of available extensional rheometers: operability diagram in terms of the fluid shear viscosity and extensional viscosity (or shear viscosity and relaxation time) of the materials that are typically measured. The $\mathrm{CaBER}^{\mathrm{TM}}$ device was developed by the Cambridge Polymer Group (MA, USA) and is commercialized by ThermoFischer (MA, USA). The FiSER ${ }^{\mathrm{TM}}$ device illustrated was developed and commercialized by the Cambridge Polymer Group. The Rheotens 71.97 device illustrated is commercialized by Göttfert (Germany).

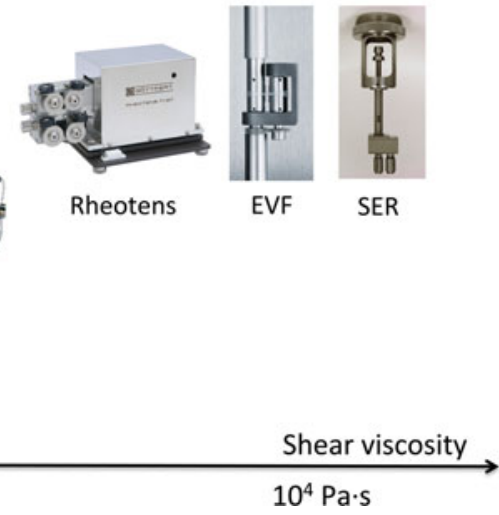

The extensional viscosity fixture $(E V F)$ is commercialized by TA Instruments (DE, USA). The Sentmanat Extensional Rheometer (SER) fixture was developed by Dr. M. Sentmanat and is commercialized by Xpansion Instruments (OH, USA) and likewise the EVF can be used as a detachable fixture on a commercial rotational rheometer. The images of FiSER ${ }^{\mathrm{TM}}$, Rheotens, EVF and SER are reproduced with permission of Cambridge Polymer Group, Göttfert, TA Instruments and Xpansion Instruments, respectively

\begin{tabular}{|l|lll|}
\hline & Journal : Large 10404 & Dispatch : 23-7-2012 & Pages : 19 \\
Article No. : 1028 & $\square$ LE & $\square$ TYPESET \\
MS Code : & $\sim_{\mathrm{CP}}$ & $\checkmark_{\text {DISK }}$ \\
\hline
\end{tabular}


significant viscoelastic effects, the inertial stresses in the fluid at such rates can completely mask the viscoelastic stresses resulting from molecular deformation, leading to erroneous results (Dontula et al. 1997; Rodd et al. 2005b). Nevertheless, although the RFX instrument is nowadays out of the market as a standalone device, it is still a subject of research and recently a new opposed-nozzle fixture, that can be mounted onto a controlled strain rheometer, was developed by Soulages et al. (2009a).

Among the plethora of techniques developed for extensional characterization of mobile liquids, reviewed by Gupta and Sridhar (1988) and McKinley and Sridhar (2002), filament stretching rheometry has sparked off great interest since the pioneering work of Matta and Tytus (1990) and Bazilevsky et al. (1990). In just one decade it matured to such an extent that in 2001 it was already considered as an accurate method for characterizing the response of viscoelastic fluids and, in particular, of viscous dilute polymer solutions, almost achieving an ideal uniaxial extensional deformation (Anna et al. 2001). According to Sridhar (2000) it represented the culmination of about four decades of intense research in the development of a suitable extensional rheometer. A major advantage is that the velocity field far from the rigid endplates is essentially one-dimensional and purely extensional (Schultz and Davis 1982). Over the past two decades different filament stretching configurations have been proposed for generating such flows, but two among those have showed enhanced performance for rheometric purposes (McKinley et al. 2001):

- The filament stretching extensional rheometer (FiS$\mathrm{ER}^{\mathrm{TM}}$ ) illustrated in Fig. 2a imposes an exponential velocity to the upper plate in order to induce a uniaxial extensional flow with constant strain rate, rather than constant tensile force, as in the original concept of
Matta and Tytus (1990). The temporal evolution of the tensile force exerted by the fluid column on the bottom endplate and of the filament radius at the axial midplane of the filament are both measured and used to compute the transient extensional viscosity (McKinley et al. 2001). A more reliable version of the FiSER ${ }^{\mathrm{TM}}$ can use a real-time algorithm to control the upper plate velocity in order to achieve the desired exponential decay of the filament diameter at the midpoint (Anna et al. 1999).

- The capillary breakup extensional rheometer $\left(\mathrm{CaBER}^{\mathrm{TM}}\right)$, based on the ideas of Bazilevsky et al. (1990), imposes an extensional step strain of order unity and the filament subsequently thins under the influence of capillary forces without additional kinematic input at the boundaries. Subsequently, the fluid filament undergoes a thinning process with an extensional strain rate defined by the extensional properties of the fluid. Large extensional strains can still be attained as the mid-region of the filament progressively necks down and eventually breaks. Typically, the only measured quantity is the time evolution of the midpoint diameter of the necking filament (see Fig. 2b) and the relaxation time is determined from the exponential decay of the filament diameter with time (McKinley et al. 2001).

The relative merits of the $\mathrm{CaBER}^{\mathrm{TM}}$ and $\mathrm{FiSER}^{\mathrm{TM}}$ apparatuses, as well as the dynamics of capillary thinning of Newtonian and non-Newtonian fluids have been discussed thoroughly by McKinley and Tripathi (2000), McKinley and Sridhar (2002) and McKinley (2005). Even though the $\mathrm{CaBER}^{\mathrm{TM}}$ can be used to measure relaxation times of viscoelastic liquids with significantly lower viscosities than the FiSER ${ }^{\mathrm{TM}}$ there is still a limit of operation,
Fig. 2 a Schematic diagram of a FiSER ${ }^{\mathrm{TM}}$ for moderately viscous materials [reprinted from Anna et al. (1999), Copyright (1999), with permission from Elsevier Science]. b Commercial $\mathrm{CaBER}^{\mathrm{TM}} 1$ apparatus (a)

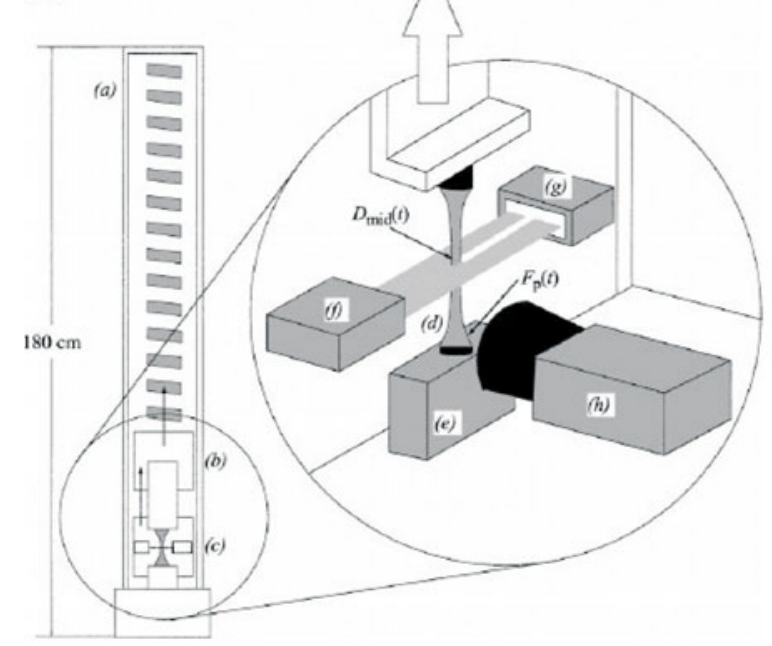

(b)

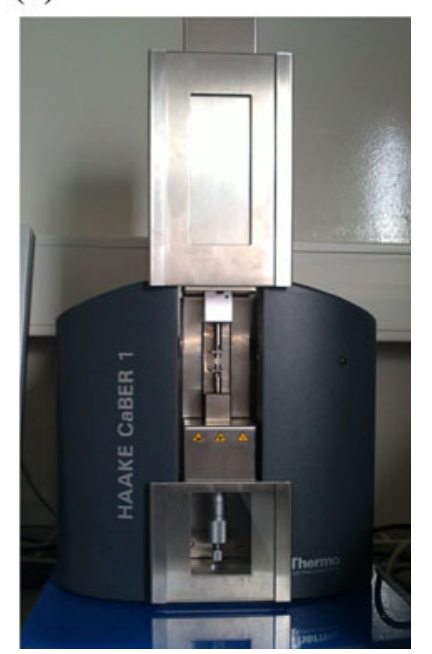


as depicted in the $\mathrm{CaBER}^{\mathrm{TM}}$ operability diagram presented by Rodd et al. (2005b). This diagram defines a minimum limit for the measurable relaxation time around $1 \mathrm{~ms}$ for liquids with a shear viscosity of about $3 \mathrm{mPa}$ s achievable by selecting appropriately the operating conditions, which in practical terms is very difficult to achieve due to strong inertial effects and the fact that the position of the narrowest part of the filament is not always matching the position of the laser micrometer. For these reasons, the use of high speed cameras for recording the filament necking process is becoming a common practice as a complementary technique for evaluating the extensional properties of low viscosity fluids and for extending the limits of reliable operation for the $\mathrm{CaBER}^{\mathrm{TM}}$ (Oliveira et al. 2005, 2006; Niedzwiedz et al. 2009, 2010; Roche et al. 2011). Recently, Campo-Deaño and Clasen (2010) presented a reliable technique to measure relaxation times in extension as low as $240 \mu$ s with the $\mathrm{CaBER}^{\mathrm{TM}}$ using a high-speed camera and a slow retraction method in order to minimize inertial oscillations originated from the acceleration of the liquid. There are also some works where micro-length scales have also been considered with the CaBER ${ }^{\mathrm{TM}}$ technique (Kojic et al. 2006; Sattler et al. 2008; Erni et al. 2011) and the range of operation was analyzed theoretically (Ardekani et al. 2010).

In spite of the ability of the filament thinning experiments to stretch significantly the samples, stress measurements indicated that the chains were not reaching their full extension (Babcock et al. 2003). Furthermore, one of the major concerns about filament stretching rheometry is related with the undesirable influence of gravitational effects, since even small gravitational forces can lead to a significant distortion of the liquid bridges (Bänsch et al. 2004).

In recent FiSER $^{\mathrm{TM}}$ experiments, the effect of predeformation history on the uniaxial extensional flow was analyzed (Anna and McKinley 2008). Recent experiments were carried out in the International Space Station inside the Microgravity Science Glovebox under the auspices of the NASA (SHERE in 2008 and SHERE II in 2011) in order to obtain material property measurements of the fluids using different rotational preshear histories and imposing different axial extensional rates (McKinley and Hall 2011a, b) without the undesirable effects of gravity.

The inherent difficulties of extensional rheometry of low-viscosity fluids due to gravitational and inertial effects can be minimized through miniaturization of rheometric instrumentation. However, the ability of macroscale systems to probe the bulk rheology of a fluid at the microscale remains limited, since the scale down of some mechanical subsystems, such as torsional motors and torque transducers, is impractical (Pipe and McKinley 2009). As an alternative approach, the use of microfluidics for rheometric purposes is very promising and has attracted the attention of several research groups.

In the present article, we discuss the important recent developments on microfluidic rheometry to generate strong extensional flows and to measure bulk rheological properties in extensional flow, and present a critical assessment of their capabilities and limitations of operation. This review complements the work by Pipe and McKinley (2009), which reviews bulk rheology measurements at the microscale, for shear and extensional flows, but focuses on capillary, stagnation and contraction flows.

\section{Microfluidics as a platform for extensional rheometry}

Microfluidics is the science and technology of systems that process or manipulate very small amounts of fluids in geometries with characteristic lengthscales ranging from tens to hundreds of micrometres, and is now established as a new field of research (Whitesides 2006). While most research in microfluidics concerns Newtonian fluids, many fluids of interest for lab-on-a-chip applications are likely to exhibit complex microstructure and non-Newtonian behavior, such as viscoelasticity (Squires and Quake 2005). The small characteristic lengthscales of microfluidics enable the generation of flows with high deformation rates while keeping the Reynolds number $(R e)$ small. These unique flow features result in the ability to promote strong viscoelastic effects, quantified by the elasticity number $(E l)$ that scales inversely with the square of the characteristic length $(L)$, which are highly enhanced as the scale is reduced. This effect is especially noteworthy for low viscosity complex fluids (e.g. inks, coating fluids, DNA solutions, etc.) (Oliveira et al. 2008b), for which the elasticity number may be small in macroscopic flows $(E l \ll 1)$, but very large at the microscale and most likely not concealed by flow inertia (Rodd et al. 2005a). Therefore, detailed understanding of the impact of fluid rheological properties on flows at such small scales is clearly desirable. These distinctive flow characteristics together with the development and growth of microfluidic techniques provide a rich platform for rheologists to perform rheometric investigations of non-Newtonian fluid flow phenomena at small scales and new opportunities for material property characterization (Soulages et al. 2009b). Moreover, due to difficulties in the measurement of rheological properties in extensional flows at the macroscopic scale, especially for low viscosity liquids (Petrie 2006; Campo-Deaño and Clasen 2010), the use of microfluidic devices to measure bulk properties in extensional flow is a promising approach and has been an active topic of research in recent years (Pipe and McKinley 2009), examples include microfluidic implementations of the four-roll mill (Lee et al. 2007), the

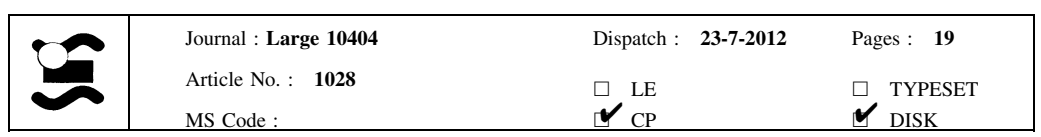


cross-slot flow geometry (Arratia et al. 2008; Alves 2008; Haward et al. 2012a), or the use of contraction flows (Rodd et al. 2007; Oliveira et al. 2007a; Campo-Deaño et al. 2011).

Based on this scenario, Pipe and McKinley (2009) reviewed recently that microfluidics can be used to determine bulk rheological properties of complex fluids, as modern microrheology does using colloidal probes suspended in the fluids (Squires and Mason 2010). Moreover, a microfluidic-based rheometer-on-a-chip has a number of practical advantages such as having no air-liquid interface, that might be of interest for use with biological fluids and fluids prone to evaporation, and additionally it could serve as an online rheological sensor in many industrial processes (Bandalusena et al. 2009), which is an important advantage relative to microrheology. Guillot et al. (2006, 2008) achieved relative success in measuring shear rheological properties in microfluidic channels. Pipe et al. (2008) were also able to measure steady shear flow curves by means of a rheometer-on-a-chip containing three flush mounted microelectromechanical systems (MEMS) pressure sensors (see Fig. 3), as used in the $\mathrm{m}_{-V_{R O C}}{ }^{\mathrm{TM}}$ microfluidic shear rheometer commercialized by Rheosense Inc. (San Ramon, CA, USA).

Summing up, the advent of microfluidic technology has not only increased the need for rheological information about diluted polymer solutions but also provided a new platform for developing and testing new rheometric devices. In particular, microfluidic stagnation and contraction flows, used for investigating the longstanding problem of the extensional behavior of low viscosity viscoelastic liquids, show great potential and are viable alternatives to conventional rheological characterization techniques. Additionally, it is a golden opportunity for computational rheologists to incorporate and test new constitutive

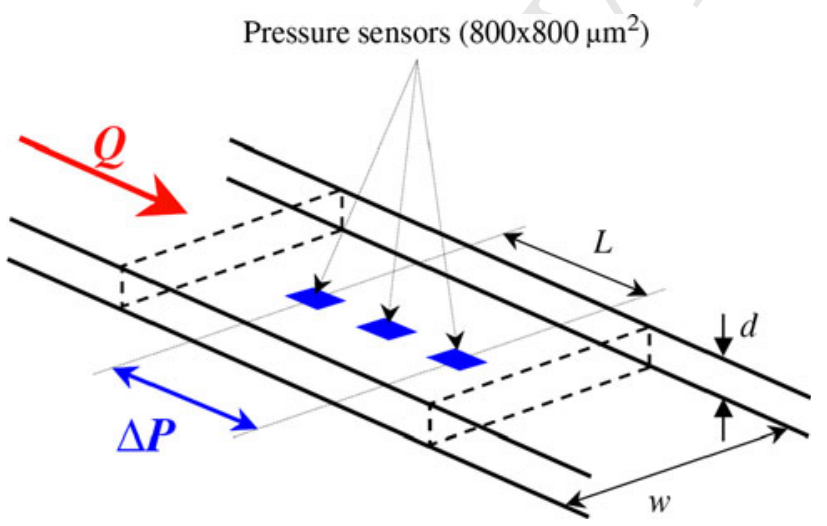

Fig. 3 Illustration of the RheoSense VROC slit microfluidic rheometer, made from Pyrex mounted on a gold-coated silicon substrate with three flush mounted MEMS pressure sensors. With kind permission from Springer Science+Business Media, Pipe et al. (2008, figure 2) equations for viscoelastic fluid modeling in complex flows, and investigate high-Weissenberg number flow conditions.

2.1 Microfluidic stagnation-point flows

A stagnation-point in a fluid flow is the location where the velocity is zero, but local extension rate can be finite (free stagnation point) or zero (pinned stagnation point) (Soulages et al. 2009b). A classical application of the stagnation-point in fluid flows is the Pitot tube used on a routine basis for measuring the flow velocity. Recently, flows with internal (or free) stagnation point, such as those generated in a four-roll mill (Taylor 1934; Lagnado and Leal 1990; Hudson et al. 2004; Pathak and Hudson 2006; Lee et al. 2007), cross-slot (Perkins et al. 1997; Remmelgas et al. 1999; Arratia et al. 2006; Odell and Carrington 2006; Poole et al. 2007; Alves 2008; Dylla-Spears et al. 2010) or T-junctions (Link et al. 2004; Soulages et al. 2009b), are increasingly popular due to the interest in understanding the flow of complex fluids under strong extensional deformations, and evaluating the extensional properties of dilute polymer solutions in particular (Becherer et al. 2008). The vorticity-free state of the flow near a free stagnation-point can result in large extensional deformation and orientation of the microstructure of complex fluids (Pipe and McKinley 2009). Another reason for the interest in stagnation-point flows is their capability to trap macromolecules or microscopic objects by purely hydrodynamic means while subjecting them to a strong extensional deformation (Tanyeri et al. 2010, 2011), as has been done with long DNA molecules (Shaqfeh 2005; Balducci et al. 2008; Dylla-Spears et al. 2010).

Theoretical modeling of stagnation-point flows has proven to be particularly challenging, and despite extensive experimental and theoretical investigation, some aspects of these complex flows remain to be elucidated (Becherer et al. 2008). In the next sections, we focus on the three configurations mostly used in microfluidics for generating stagnation-point flows and we summarize their capabilities and limitations for characterizing extensional properties of low viscosity fluids.

\subsubsection{Microfluidic four-roll mill}

The four-roller apparatus (cf. Fig. 4), commonly known as four-roll mill, was invented by Taylor (1934) during his investigations on the stirring process to generate emulsions of two immiscible fluids. This device consists of four cylinders arranged in a square configuration which rotate inside a container filled with fluid. A four-roll mill has the ability to generate different flow kinematics ranging from pure extension, to shear, or to pure rotation, through an appropriate choice of speed and direction of rotation of the 


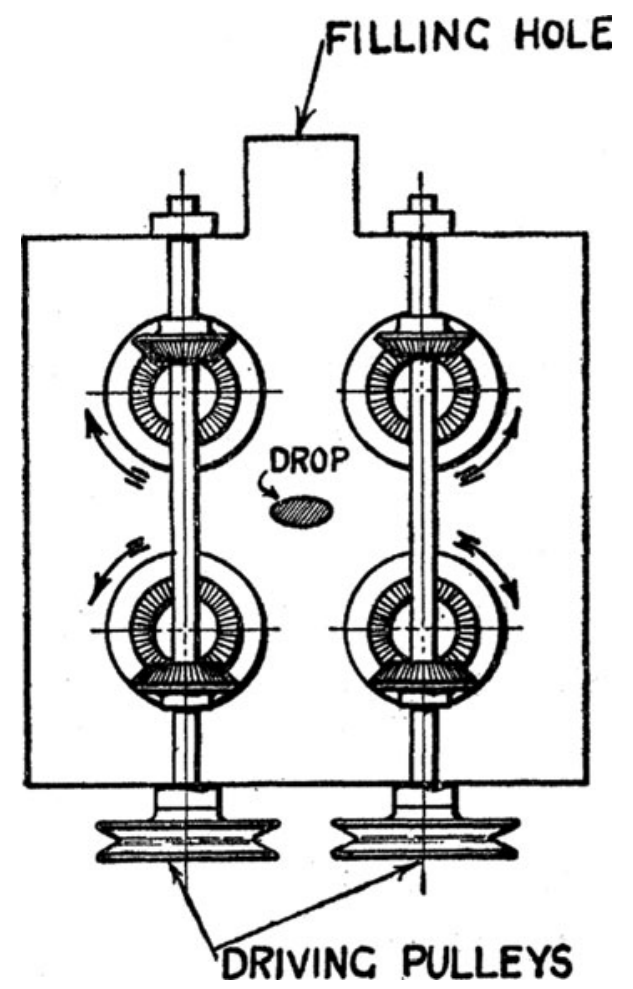

Fig. 4 Original sketch of the "four-roller apparatus". Reproduced with permission from Taylor (1934)

four cylindrical rollers (the apparatus of Fig. 4 is less versatile because the four cylinders cannot be driven independently). Among the wide variety of homogeneous two-dimensional flows that can be produced with a fourroll mill apparatus, the quasi-two-dimensional extensional flow in the central region between the rollers is only one particular case, as highlighted by Lagnado and Leal (1990). Therefore, in principle, combining the capabilities of the four-roll mill and the low inertia flow conditions of microfluidics would offer the possibility of measuring the extensional properties of low viscosity fluids and analyze the response of single molecules under strong extensional flow. However, developing a microfluidic four-roll mill is a challenging task.

Hudson et al. (2004) and Phelan Jr. et al. (2005) developed an ingenious microfluidic design of an analog of the four-roll mill, consisting of six intersecting channels with asymmetric configuration (see Fig. 5). By choosing the appropriate flow rate in each channel, they showed that it is possible to create in this geometry a central stagnation point around which the flow type could be varied from pure extension to nearly pure rotation, including simple shear flow conditions (Hudson et al. 2004; Pathak and Hudson 2006). However, this microfluidic device has two major drawbacks: pure rotation cannot be obtained due to the asymmetry of the geometry (Lee et al. 2007), and the aspect ratio of the device (depth/width, $h / w$ ) must be

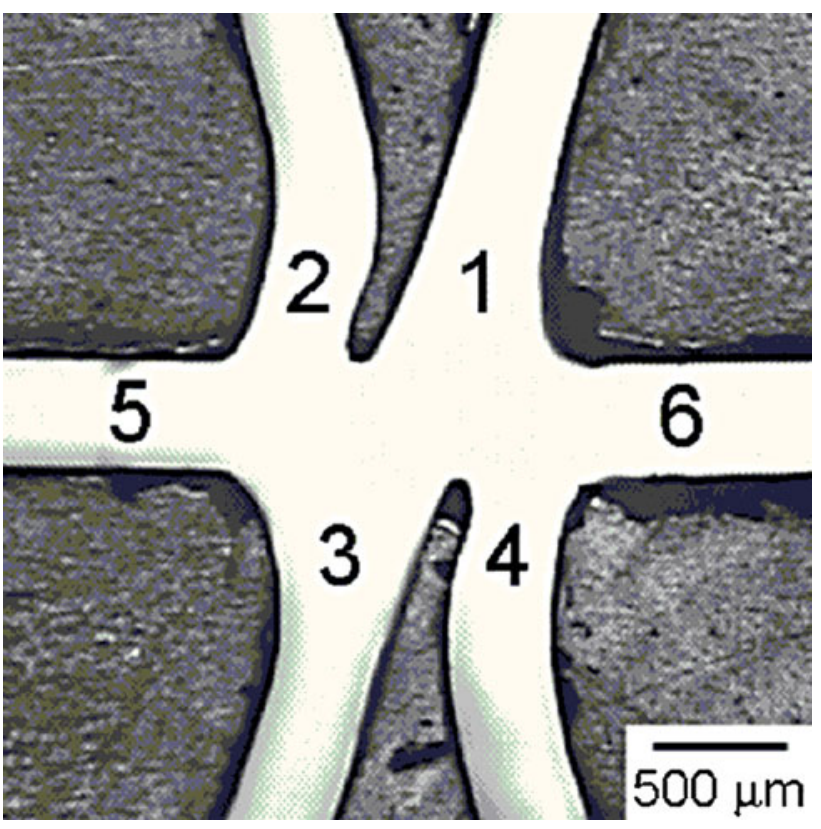

Fig. 5 Microfluidic analog of the four-roll mill proposed by Hudson et al. (2004). Reprinted with permission from Hudson et al. (2004), Copyright (2004), American Institute of Physics

greater than unity to generate substantial rotation (Hudson et al. 2004).

Lee et al. (2007) proposed another microfluidic analogue of a four-roll mill able to keep geometrical symmetry around the stagnation point and to access the full spectrum of flow types, ranging from pure rotation to pure extension, using different aspect ratios of the channel. This microfluidic four-roll mill analogue consists of four inlet and four outlet streams arranged in pairs and disposed symmetrically with regards to the central cavity, as shown in Fig. 6. In comparison with the original design of Hudson et al. (2004), the drawbacks previously mentioned were overcome, since this design is able to achieve pure rotation even with a modest aspect ratio $(h / w \approx 2)$, and much lower aspect ratios can be used. Additionally, controlling the flow type becomes easier in this device.

\subsubsection{Cross-slot microdevices}

Among the microdevices that generate stagnation-point flows, the cross-slot device is probably the configuration which has attracted most attention due to its simple geometry and easy control. The standard cross-slot consists of four channels connecting at the same point, arranged orthogonally in the same plane, as illustrated in Fig. 7. The channels can have square, rectangular or circular crosssections and the space in the chamber can vary in different configurations. When the fluid is injected in two opposing channels at the same flow rate, the opposing fluid streams

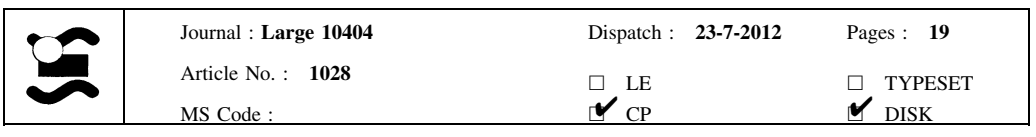




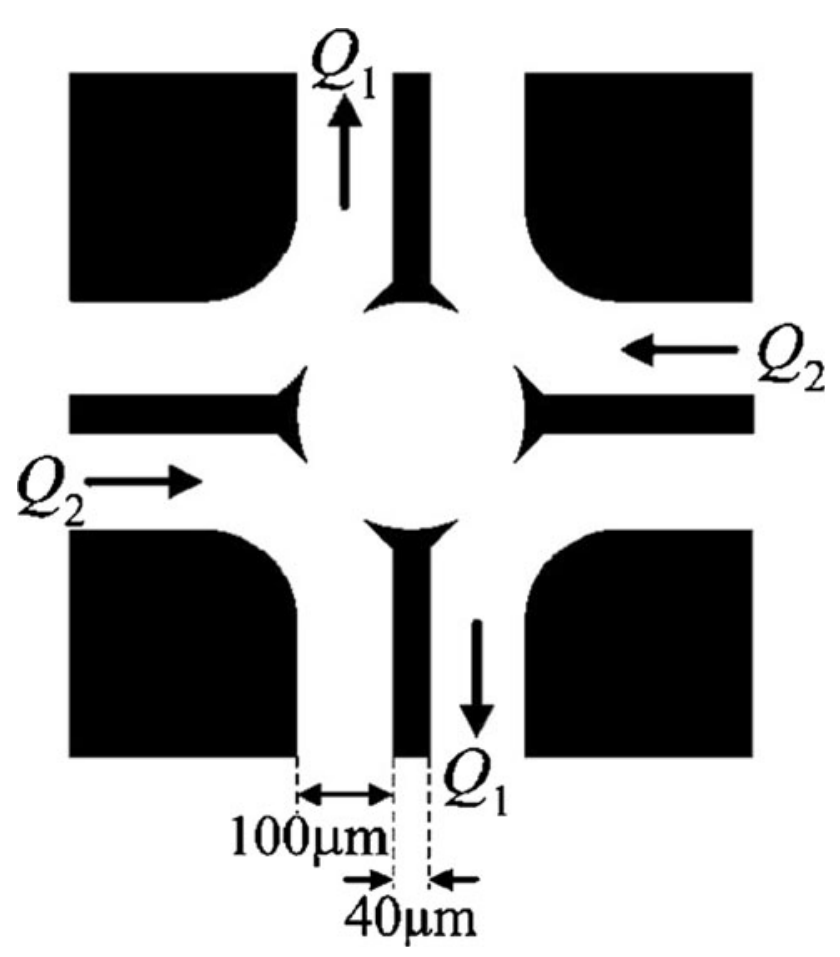

Fig. 6 Schematic diagram of a microfluidic four-roll mill device. Varying the flow rate ratio $Q_{2} / Q_{1}$ allows to generate all flow types. Reprinted with permission from Lee et al. (2007), Copyright (2007), American Institute of Physics

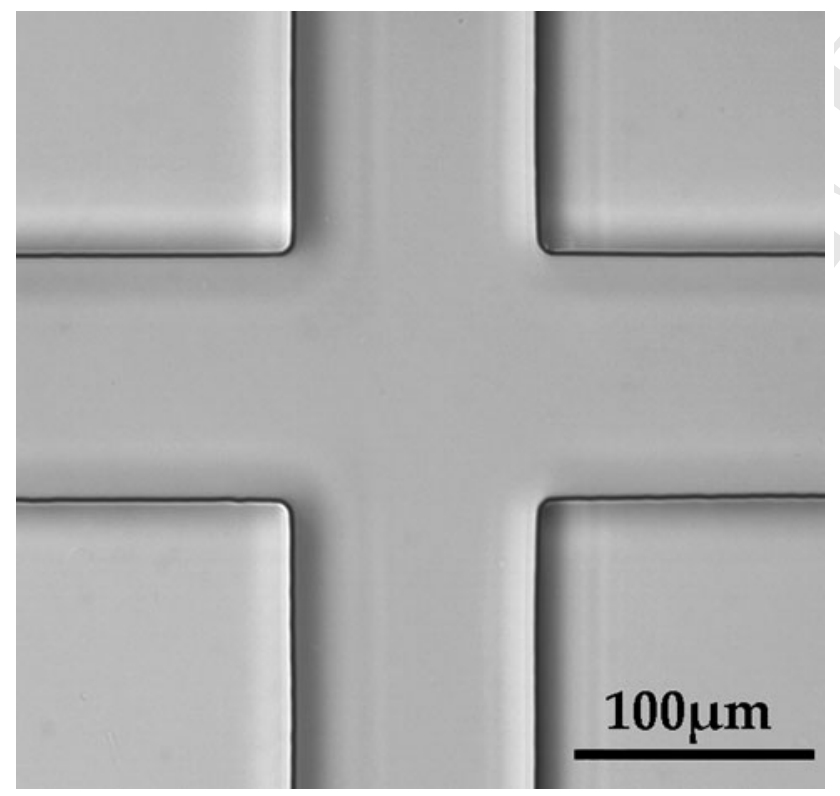

Fig. 7 Bright field image of a standard cross-slot microchannel

collide to produce a well-defined stagnation point located at the center of the geometry (if the exit flow rates are also the same), and a strong planar extensional flow is produced in the orthogonal direction while the fluid exits the chamber. Due to these flow characteristics, the standard crossslot has been used to trap and stretch single molecules, as done by Dylla-Spears et al. (2010) who investigated the behavior of double-stranded genomic DNA for detection of target sequences along the DNA backbone. The cross-slot microdevice has also been used for analyzing elastic instabilities of polymeric solutions in a planar extensional flow (Arratia et al. 2006; Haward et al. 2012a), which can also be used to induce enhanced mixing at microscale (Squires and Quake 2005).

Based on the standard cross-slot configuration, Odell and Carrington (2006) proposed the combination of oscillatory flow with a stagnation point extensional flow field to measure the extensional viscosity of low viscosity fluids. Their extensional flow oscillatory rheometer (EFOR), shown in Fig. 8, consists of a standard cross-slot cell, where the planar extension is created, having four micropumps positioned at the end of each channel. These micropumps are driven electronically and can induce any cyclic or constant flow rate profile as required, thus controlling the imposed strain and strain-rate. It is also equipped with pressure transducers in two of its limbs to record flow resistance measurements and thus provide information on the apparent extensional viscosity. In addition, by means of an optical probe to measure birefringence, the flow field stability, microstructure and molecular orientation data can be recorded simultaneously. This opto-microfluidic technique has been used in the characterization of both the shear and the extensional response of low-viscosity polymer solutions (Haward 2010; Haward et al. 2011). Moreover, the oscillatory extensional flow technique has potential applications beyond the measurement of extensional viscosity of low viscosity fluids (Odell and Carrington 2006). For instance, it can be used to investigate thermo-mechanical degradation of polymers, or even model extensional and shear flows occurring in porous media flows in tertiary oil-recovery by means of imposing customized flow profiles. Up to the current date the EFOR seems to be the paradigm of the combination between microfluidics and optical techniques for application in rheometry. Its major limitations are related to the capacity of the piezopumps and the pressure transducers, as well as the size of the cross-slot cell, which define the limits of the scale ranges and resolution for the imposed strain rates, inertial forces (Reynolds number) and pressure drop (Odell and Carrington 2006). We note that in the cross-slot chamber the planar extensional flow is not ideal, due to the shear component introduced by the bounding walls.

Computational rheologists have also shown interest in the cross-slot cell for assessing the performance of constitutive models, through comparison with experimental results (Remmelgas et al. 1999), or for gaining insight about purely elastic flow instabilities (Poole et al. 2007). Alves (2008) presented an integrated optimization algorithm able to find an efficient design of the shape of the flow geometry in order

\begin{tabular}{|l|lll|}
\hline & Journal : Large $\mathbf{1 0 4 0 4}$ & Dispatch : 23-7-2012 & Pages : $\mathbf{1 9}$ \\
Article No. : $\mathbf{1 0 2 8}$ & $\square$ LE & $\square$ TYPESET \\
MS Code : & $\sim_{\mathrm{CP}}$ & $\checkmark$ DISK \\
\hline
\end{tabular}


Fig. 8 Illustration of the EFOR set-up. Reprinted from Odell and Carrington (2006), Copyright (2006), with permission from Elsevier Science

Fig. 9 Illustration of the a initial flow configuration, b the optimized flow geometry obtained using an optimal shape design technique and $\mathbf{c}, \mathbf{d}$ the numerically predicted velocity profiles along the vertical centerline for Newtonian and viscoelastic fluids. Reprinted with permission from Alves, (2008), Copyright (2008), American Institute of Physics

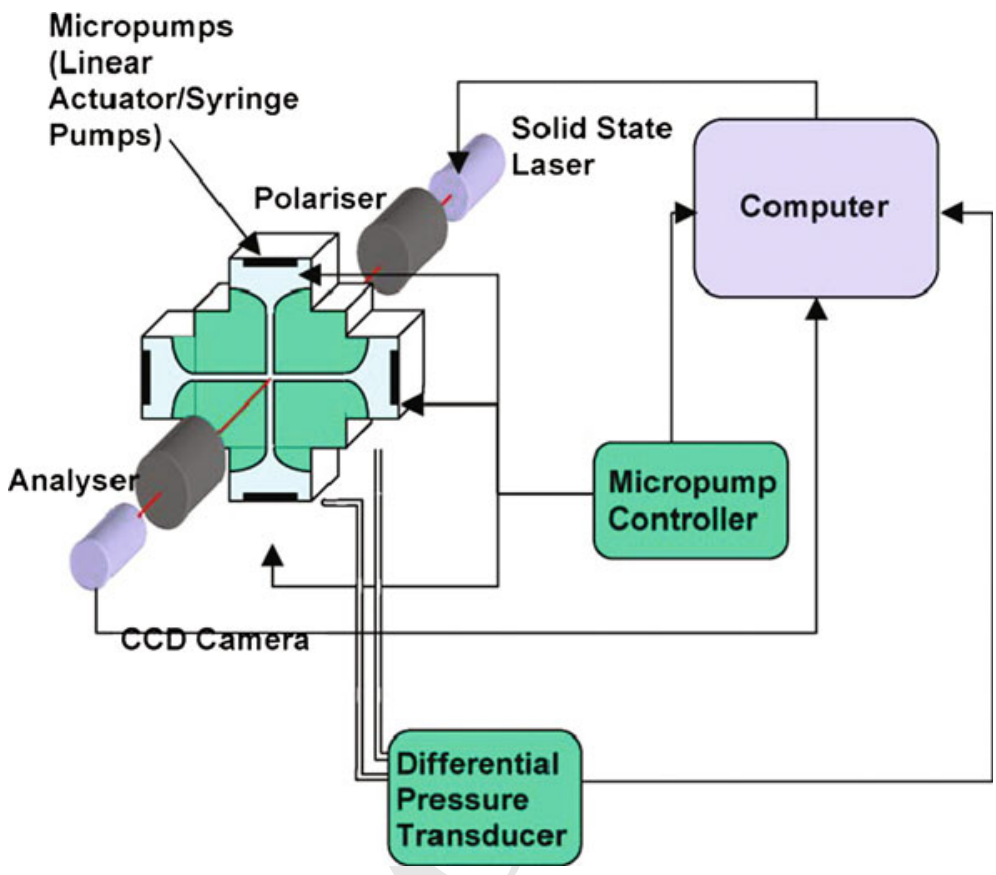

(a)

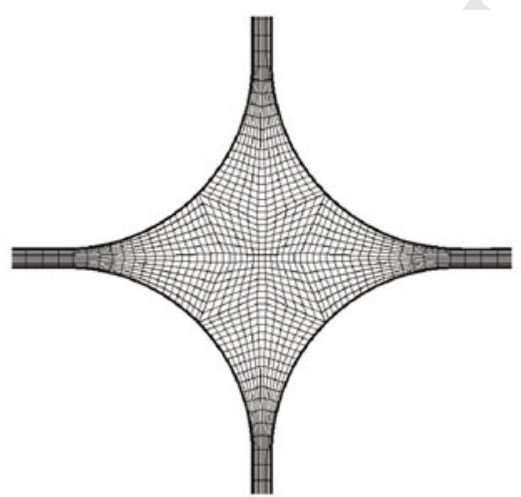

(c)

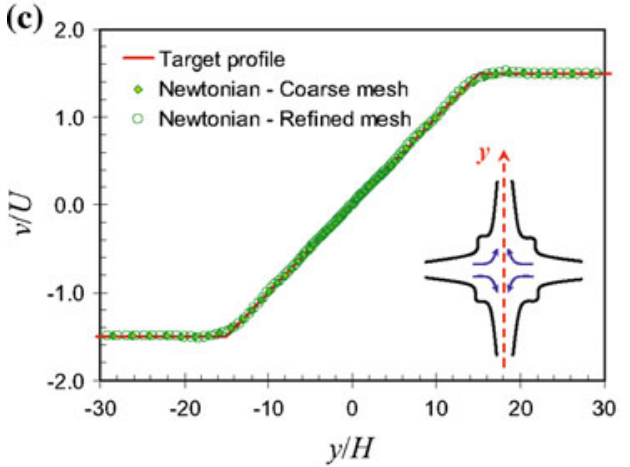

(b)

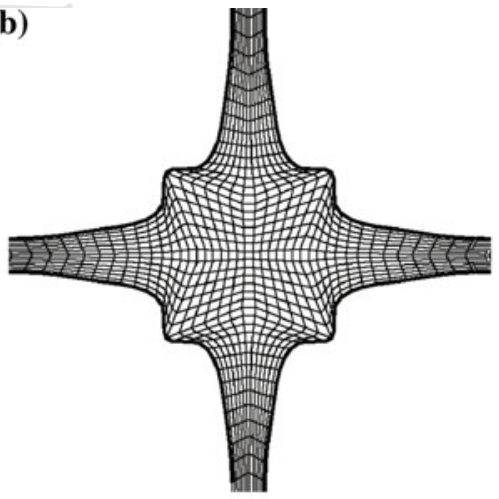

(d)

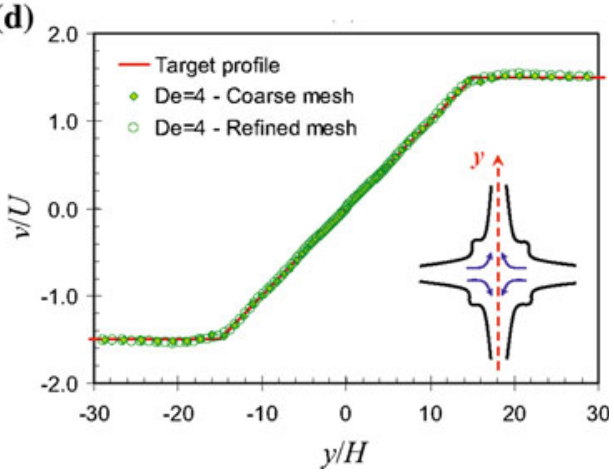

to achieve optimal performance. The standard two-dimensional cross-slot with rounded corners was used by Alves (2008) as initial guess and the optimal shape of the chamber was determined in order to obtain an ideal planar extensional flow along the flow centerlines (see Fig. 9). Recently, the optimized microfluidic device was shown to achieve a quasihomogeneous elongational flow, a crucial requirement to produce meaningful rheological measurements (Haward et al. 2012b).

\subsubsection{T-shaped microchannels}

T-shaped microchannels have been used for multiple purposes, including the generation of micro-droplets in

\begin{tabular}{|l|lll|}
\hline & Journal : Large 10404 & Dispatch : 23-7-2012 & Pages : $\mathbf{1 9}$ \\
Article No. : $\mathbf{1 0 2 8}$ & $\square_{\mathrm{CP}}^{\mathrm{LE}}$ & $\square_{\text {TISESET }}^{\text {TYPESET }}$ \\
\hline
\end{tabular}


Fig. 10 Comparison of experimental pathlines and numerical simulations (blue solid lines) using the simplified Phan-Thien-Tanner (sPTT) for the microchannels a with and b without cavity under the same flow conditions. Reprinted from Soulages et al.

(2009b),Copyright (2009), with permission from Elsevier Science (color figure online)
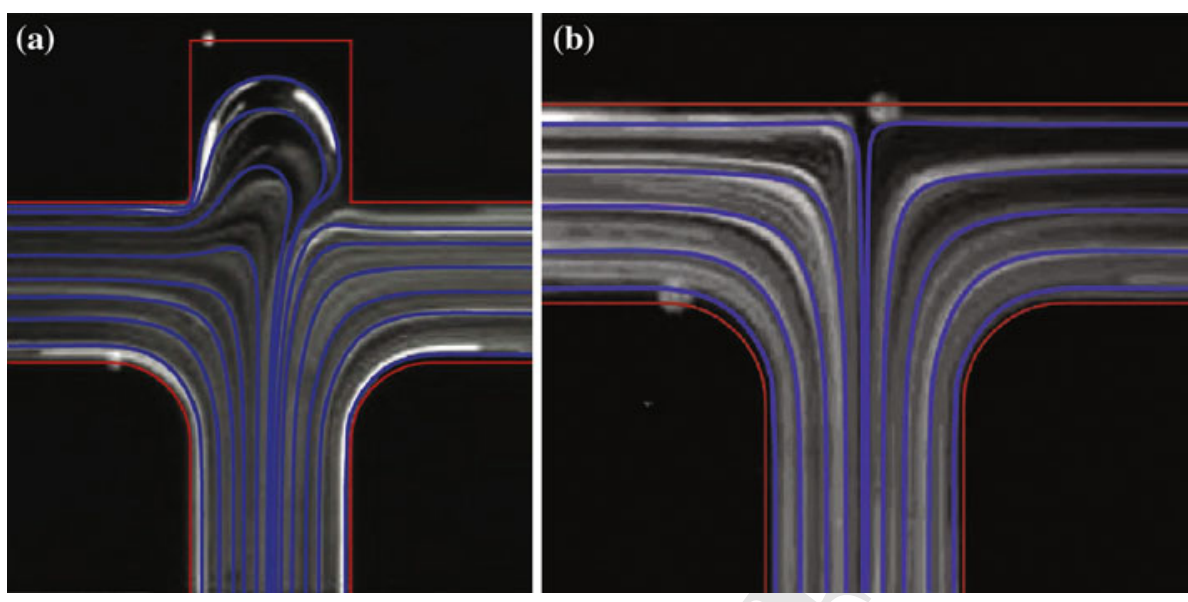

Fig. 11 a Operational regions in the Wi-Re parameter space and $\mathbf{b}-\mathbf{d}$ sketch of several canonical contractionexpansion arrangements investigated at the microscale using complex fluids Adapted from Oliveira et al. (2012)

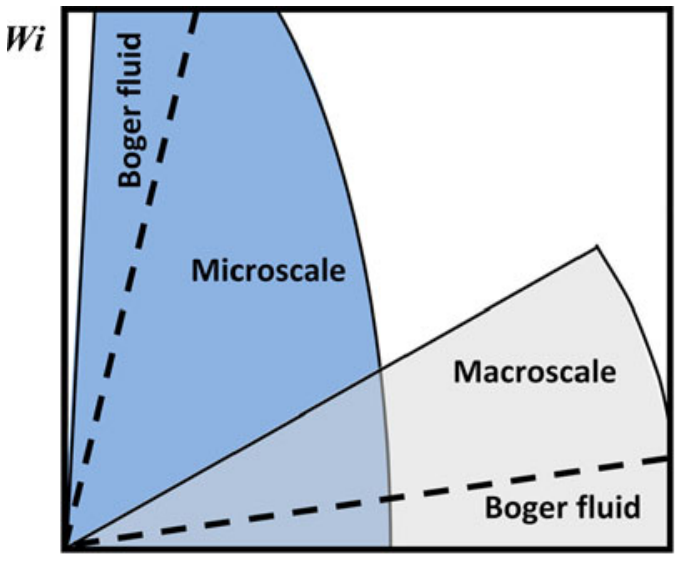

(a)
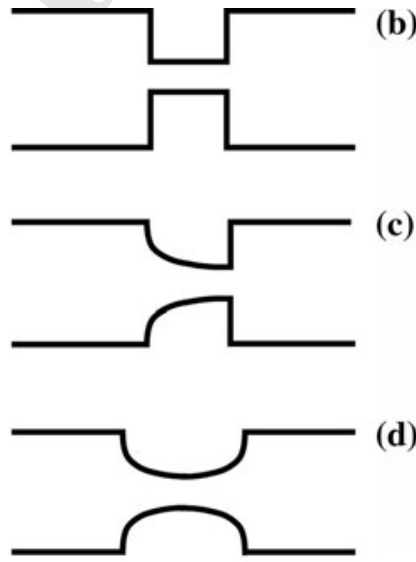

(d) microfluidic devices (Husny and Cooper-White 2006), the study of elastic driven instabilities (Soulages et al. 2009b), and for use as passive micro-mixers (Hsieh and Huang 2008). Soulages et al. (2009b) used two distinct T-shaped microchannels (with and without a small cavity), as illustrated in Fig. 10, to investigate the onset of elastically driven flow asymmetries in steady strong extensional flows. Numerical computations and experiments using streak-imaging and micro-particle image velocimetry ( $\mu \mathrm{PIV}$ ) with the T-shaped microchannels showed good agreement and allowed to gain insights about the influence of kinematics near the stagnation point in the resulting polymeric stress fields, and control the critical conditions and spatio-temporal dynamics of the resulting viscoelastic flow instabilities. Despite the partial success in the simulation of complex fluid flow in T-shaped microchannels, their use for the characterization of extensional properties of low viscosity fluids is still unexplored.

\subsection{Microfluidic contraction-expansion flows}

Even though flows of complex fluids in converging-diverging microdomains may differ from their counterparts at macroscale there is a common feature: it is a complex flow containing shear-dominated regions near the walls and nonhomogeneous extension along the centerline, with a positive strain rate upstream of the contraction plane and a negative strain rate downstream of the expansion (Rothstein and McKinley 1999, 2001). In the pursuit of developing an efficient microfluidic rheometer-on-a-chip, capable of achieving high strain rates in such a way that it can be used to measure the extensional properties of low viscosity complex fluids, the use of a microfabricated geometry containing a contraction-expansion section is becoming a classical approach after the pioneering works of Rodd et al. (2005a, 2007). At the microscale the small characteristic lengthscales enhance the elasticity of the flow $\left(E l=W i / R e=\frac{\lambda \eta}{\rho L^{2}}\right)$ and allow to reach unexplored regions in the Weissenberg number - Reynolds number $(W i-R e)$ parameter space, as shown in Fig. 11a (Rodd et al. 2007; Oliveira et al. 2012). In this section, we review the microfluidic contraction-expansion microgeometries frequently used in the characterization of extensional properties of low viscosity fluids, which are illustrated in Fig. 11b-d.

Abrupt contraction-expansion geometries have been used extensively to investigate non-linear flow phenomena associated with fluid elasticity in converging flows at the
529

530

531

532

533

534

535

536

537

538

539

540

541

542

543

544

545

546

547

548

549

550

551

\begin{tabular}{lll} 
Journal : Large 10404 & Dispatch : 23-7-2012 & Pages : $\mathbf{1 9}$ \\
Article No. : $\mathbf{1 0 2 8}$ & $\square$ LE & $\square$ TYPESET \\
MS Code : & $\square_{\text {CP }}$ & $\checkmark$ DISK \\
\hline
\end{tabular}


Fig. 12 a Schematic diagram of the planar microfluidic contraction-expansion. b Comparison between Newtonian (right) and viscoelastic (left) planar entry flows at similar $R e$ in a $16: 1$ contraction-expansion (flow is from left to right). Reprinted from Rodd et al. (2005a), Copyright (2005), with permission from Elsevier Science

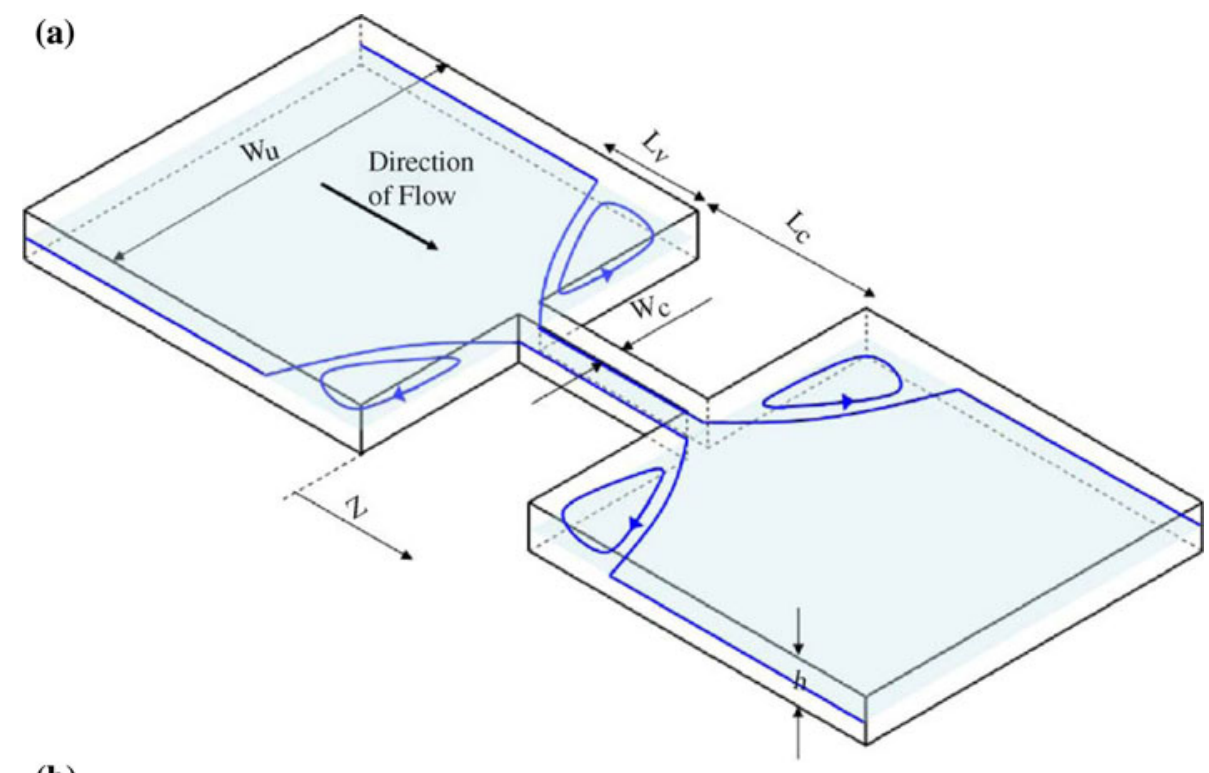

(b)

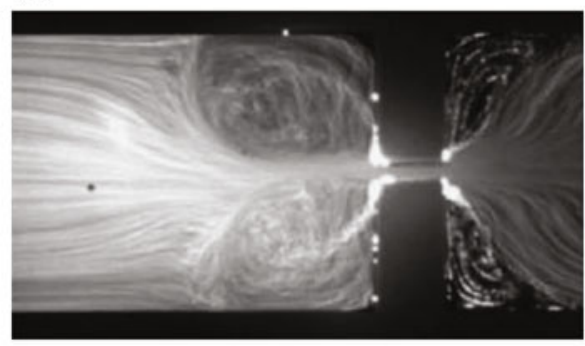

$R e=56, W i=212$

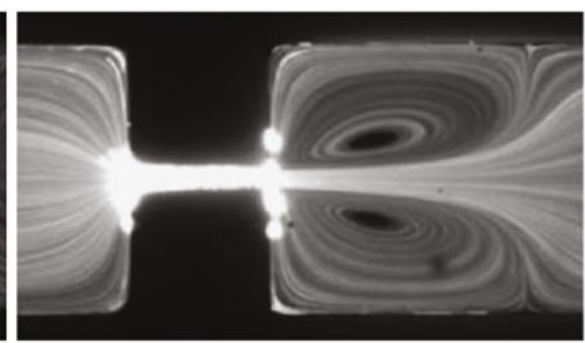

$\boldsymbol{R e}=\mathbf{5 9}$ macroscale. However, as previously mentioned, at macrolengthscales it is not possible to characterize the extensional properties of low viscosity dilute polymer solutions with relaxation times of the order of milliseconds due to the small relative importance of elastic stresses compared to inertial stresses, leading to low values of the elasticity number. However, at the microscale, the elasticity number for the same fluid is much larger and it is possible to observe elastic effects in the flow patterns imaged using streak photography (Rodd et al. 2005a). Figure 12 illustrates the formation of vortices upstream of a microfluidic planar contraction, a well-known feature of viscoelastic fluid flows (Bird et al. 1987). Furthermore, elasticity dims the formation of inertia-driven downstream vortices (Oliveira et al. 2007b; Sousa et al. 2011). Moreover, from a rheometric point of view, this geometry allows for the control of the strain rate by changing the flow rate (Oliveira et al. 2008b).

The ability to determine the excess pressure drop across the contraction-expansion suggests that these devices can be used to develop microfluidic extensional rheometers (Rodd et al. 2005a). However, the flow disturbance induced by the presence of the pressure taps introduced at the channel walls can lead to important errors in the pressure drop measurements, an effect that is known as the pressure-hole error (Tanner 1988). To overcome this problem, pressure sensors embedded in the surface of the channels could be used as in the Rheosense VROC ${ }^{\mathrm{TM}}$ (Pipe et al. 2008). Another drawback of using the abrupt contraction-expansion geometry as a microfluidic extensional rheometer is that the strain rate along the centerline is not constant. In order to minimize this limitation, a more interesting configuration would be a contraction-expansion with a hyperbolic shape, as shown in Fig. 13. The use of hyperbolic contractions results in a quasi-homogeneous extensional flow within the central part of the contraction geometry, and the total Hencky strain experienced by a fluid element is given by $\epsilon_{H}=\ln \left(D_{1} / D_{2}\right)$, where $D_{1}$ and $D_{2}$ are the widths of the large and narrow sections of the hyperbolic contraction, respectively. Higher Hencky strains lead to wider regions of constant strain rate in the center of the contraction, although entrance and wall effects are not totally avoided (Oliveira et al. 2007a).

Recently, Campo-Deaño et al. (2011) assessed the capabilities of using an hyperbolic contraction-abrupt expansion geometry as an extensional microrheometer. The relaxation times of low viscosity Boger fluids were estimated by means of the critical Deborah number for the

\begin{tabular}{|l|lll|}
\hline & Journal : Large 10404 & Dispatch : 23-7-2012 & Pages : $\mathbf{1 9}$ \\
Article No. : $\mathbf{1 0 2 8}$ & $\square_{\mathrm{CP}}^{\mathrm{LE}}$ & $\square_{\text {TISESET }}^{\text {TYPESET }}$ \\
\hline
\end{tabular}


Fig. 13 Flow patterns for a $50 \mathrm{ppm}$ polyacrylamide aqueous solution with $1 \% \mathrm{NaCl}$ at different flow rates. The flow direction is from left to right at the Reynolds and Deborah numbers indicated. Reprinted from Campo-Deaño et al. (2011), Copyright (2011), with permission from Elsevier Science

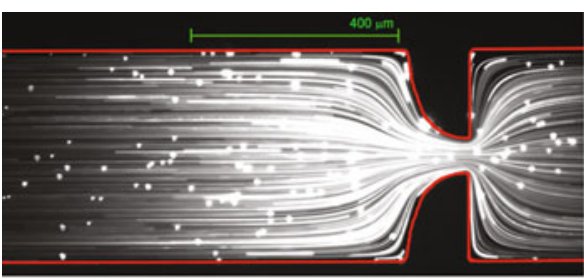

(a) $0.40 \mathrm{ml} / \mathrm{hr} ; R e=2.46 ; D e=1.19$

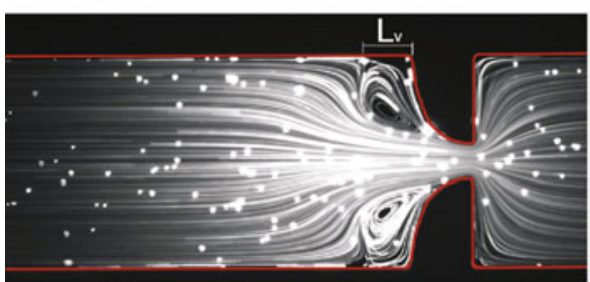

(c) $1 \mathrm{ml} / \mathrm{hr} ; R e=6.16 ; D e=2.98$

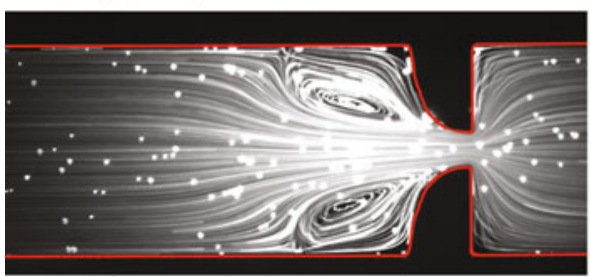

(e) $1.5 \mathrm{ml} / \mathrm{hr} ; R e=9.24 ; D e=4.47$

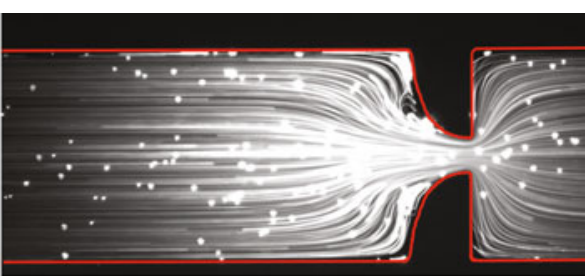

(b) $0.75 \mathrm{ml} / \mathrm{hr} ; R e=4.62 ; D e=2.24$

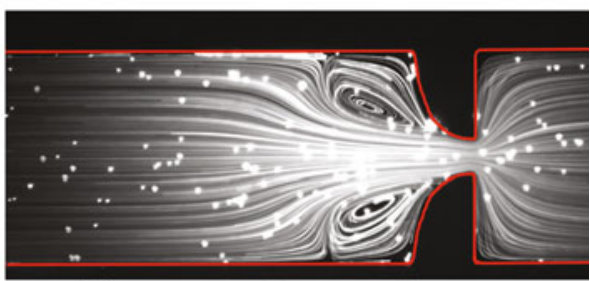

(d) $1.25 \mathrm{ml} / \mathrm{hr} ; R e=7.70 ; D e=3.73$

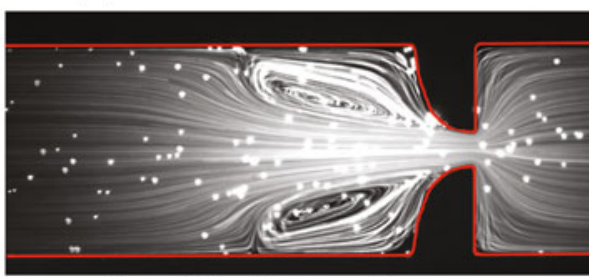

(f) $2 \mathrm{ml} / \mathrm{hr} ; R e=12.3 ; D e=5.96$ (a)

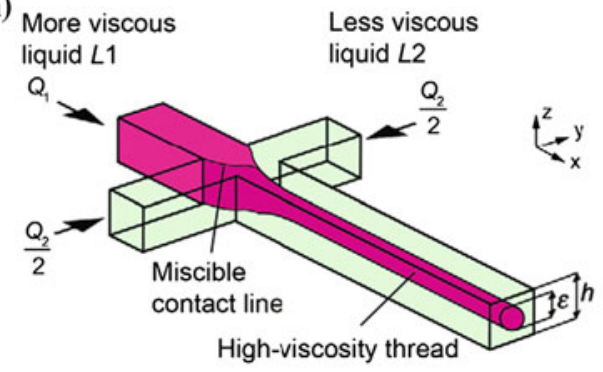

Fig. 14 Formation of threads of a core fluid lubricated with a miscible fluid. a Schematic three-dimensional view, b, c experimental micrographs of miscible contact lines for different flow rate ratios onset of secondary flow upstream of the contraction plane, which is assumed to be only weakly dependent on the polymer concentration, at least when inertial effects are negligible (see Fig. 13). One important limitation is that this microgeometry is only suitable for Boger-like fluids, since the presence of shear thinning behavior would make the analysis more complex and eventually trigger the onset of secondary flow downstream of the expansion plane.

\subsection{Microfluidic flow focusing devices}

In microfluidic flow focusing devices the shear effects occurring at the walls can be minimized by introducing a lubricating sheath fluid allowing to obtain a shear-free elongational flow on the core fluid, as illustrated in Fig. 14. In this section, we review different geometrical (b)

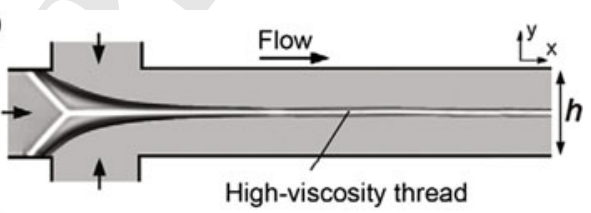

(c)

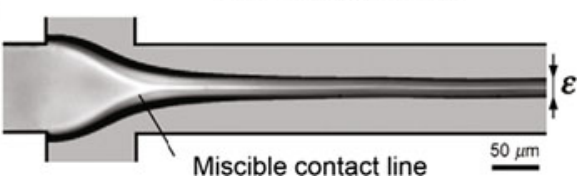

$\left(\phi=Q_{1} / Q_{2}\right): \mathbf{b} \phi=0.01$, c $\phi=0.20$. Reprinted from Cubaud and Mason (2009). Copyright (2009), with permission from IOP Publishing Ltd

configurations used in flow focusing devices with application in extensional rheometry, highlighting two key aspects for the success in the development of an extensional microrheometer: the miscibility between the fluids and the geometrical shape of the microfluidic device.

The miscibility between the core and the lubricating fluids is a crucial parameter to take into account when the working fluids are different. When the fluids are miscible, the lubricating fluid encapsulates the core fluid producing a thread, as shown in Fig. 14a. From the perspective of developing an extensional microrheometer using a flow focusing device, this is very interesting, since the lubricant fluid wraps around the core fluid and forms a thread that fully detaches from the bounding walls, generating a truly shear-free uniaxial extension, neglecting the shear in the interface between both fluids, which is a reasonable

\begin{tabular}{|l|ll|}
\hline Journal : Large $\mathbf{1 0 4 0 4}$ & Dispatch : 23-7-2012 & Pages : 19 \\
Article No. : $\mathbf{1 0 2 8}$ & $\square$ LE & $\square$ TYPESET \\
MS Code : & $\sim_{\text {CP }}$ & $\checkmark$ DISK \\
\hline
\end{tabular}




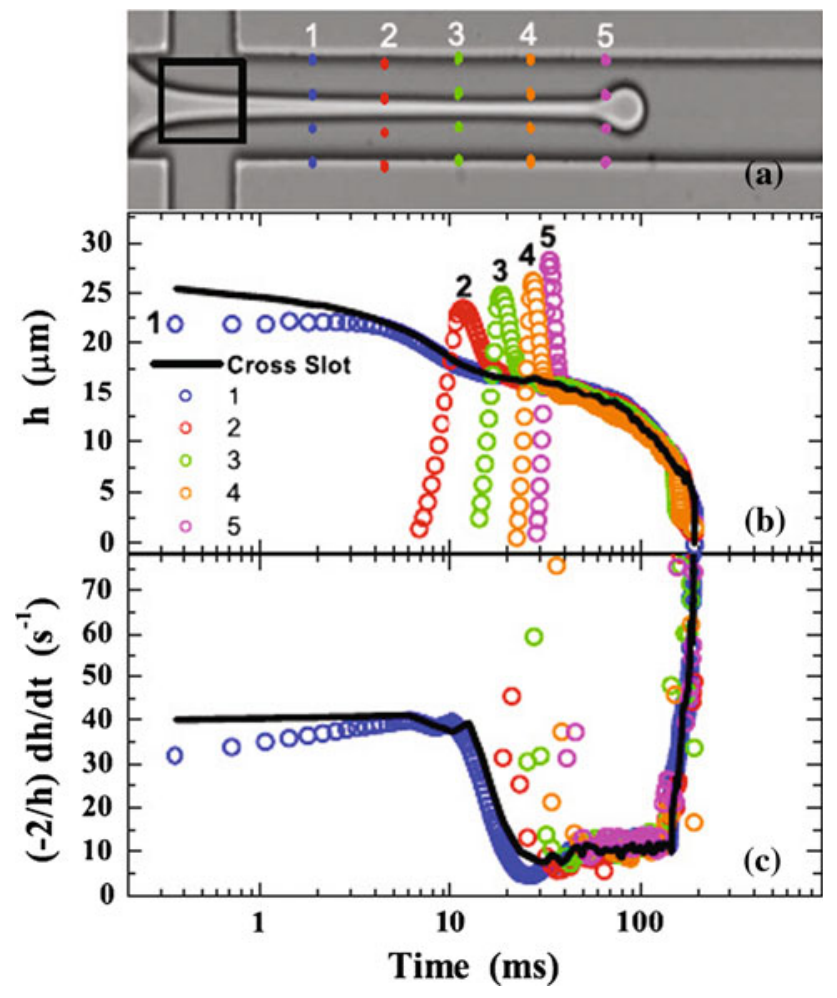

Fig. 15 a Filament thickness of a polyacrylamide solution, $h(t)$, measured at different locations in the cross-slot microchannel. A mineral oil is used as lubricating fluid. Measurements are performed in the central region (square) and at (dashed) lines 1-5. b Filament thickness of the polymeric solution at a constant flow rate measured at different locations. Data color is shown in a. c Computed extensional strain rate, $\dot{\epsilon}$, for the cases illustrated in $\mathbf{b}$. The data show that the measurements of $h(t)$ are nearly independent of axial position, after an initial transient period. Reprinted with permission from Arratia et al. (2008). Copyright by the American Physical Society (color figure online)

approximation for low viscosity lubricating fluids. There is an optical signature of the thread encapsulation given time evolution of the thickness of the filament, $h(t)$, at the mid-plane of the microchannel $(z=H / 2)$ was recorded and the extensional strain rate was calculated as $\dot{\epsilon}=-(2 / h) \frac{\mathrm{d} h}{\mathrm{~d} t}$. Their results suggest that the steady-state extensional viscosity can be estimated from the exponential rate of thinning. In spite of this breakthrough, one must take into account two key features for having success in the measurement of the steady-state extensional viscosity of the core fluid using this technique:

- The generated filament of the core fluid is not a thread, as occurs in the CaBER but rather a sheet (Cubaud and Mason 2009) having the height of the channel and a thickness that varies ideally only with time. However, depending on the interfacial tension between the core and the lubricating fluids, the thickness can also vary throughout the depth of the channel.

- The depth of the microchannel is also an important parameter, since the top and bottom walls of the microchannels influence the kinematics of the flow at the mid-plane. If the aspect ratio of the channel (depth/ width) is not sufficiently large, it is not possible to achieve a shear-free flow at the mid-plane.

In pursuing the understanding of the interplay between viscoelasticity and surfactant dynamics in thread formation and stretching processes in a flow focusing microdevice, Lee et al. (2011) analyzed the ability of viscoelasticity to enhance the formation of jets and long threads. Their analysis focused on the control of droplet formation in flow focusing microdevices, but also showed up to what extent relaxation times extracted from thread formation depend on interfacial properties between the two fluids, which influence the thread formation and breakup mechanisms and may lead to mismatching results.

The double-cross-slot, used by Oliveira et al. (2008a), is another promising approach to generate a shear-free extensional flow with nearly constant strain rate. This device consists of three entrances and three exits disposed in a symmetric configuration, as illustrated in Fig. 16a. By means of numerical calculations, Oliveira et al. (2008a) analyzed the effect of velocity ratio $\left(\mathrm{VR}=U_{2} / U_{1}\right.$, where $U_{1}$ and $U_{2}$ are the inlet average velocities of the core and lubricating fluids, respectively), geometric parameter $\left(\mathrm{WR}=D_{2} / D_{1}\right)$ and Deborah number $\left(D e=\lambda U_{1} / D_{1}\right)$ on the flow patterns and velocity field for creeping flow conditions in two-dimensional geometries. In Oliveira et al. (2009), a similar flow focusing device with three entrances and a single exit is also analyzed numerically. One advantage of the double cross-slot is that the Hencky strain can be adjusted by varying either VR or WR, since $\epsilon_{H}=\ln [3(1+2 \mathrm{VR} \times$ WR)/2], and varying VR is straightforward and does not require any change to the microchannel. In this way, using
672

673

674

675

676

677

678

679

680

681

682

683

684

685

686

687

688

689

690

691

692

693

694

695

696

697

698

699

700

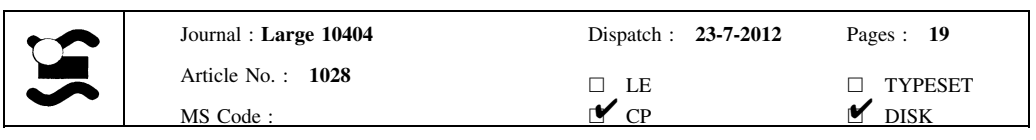


Fig. 16 a Sketch of the double cross-slot geometry. b Influence of velocity ratio (VR) on the flow patterns and $\mathbf{c}$ the axial velocity profiles along the centerline for $D_{1}=D_{2}$ and $D e=0.2$. Reprinted with permission from Oliveira et al. (2008a), Copyright (2008),

American Institute of Physics (a)

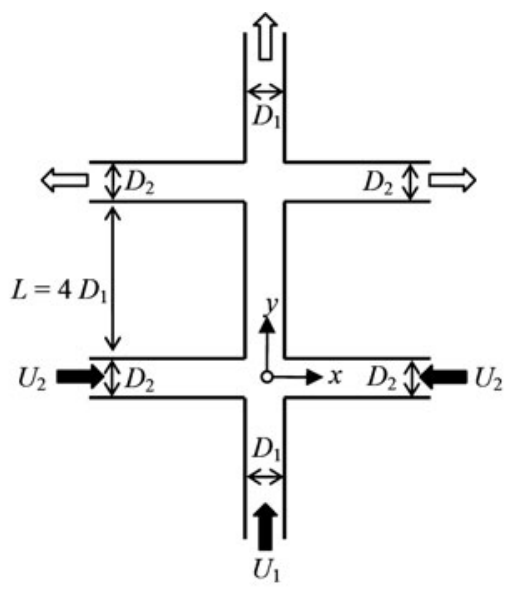

(b)

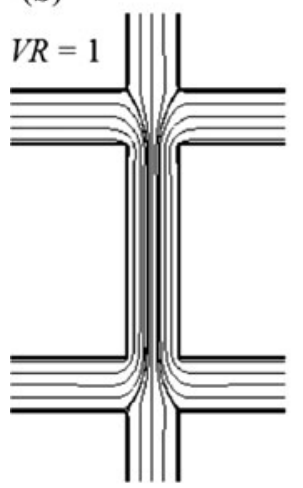

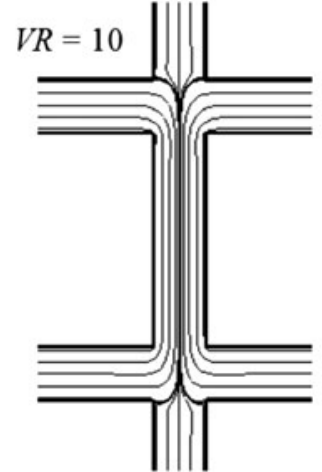

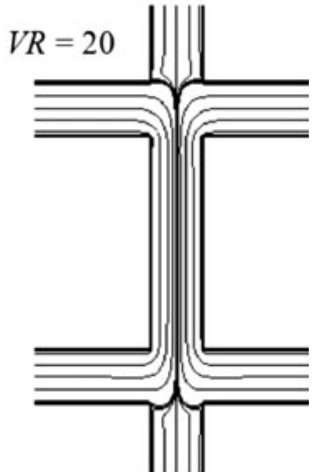

(c)

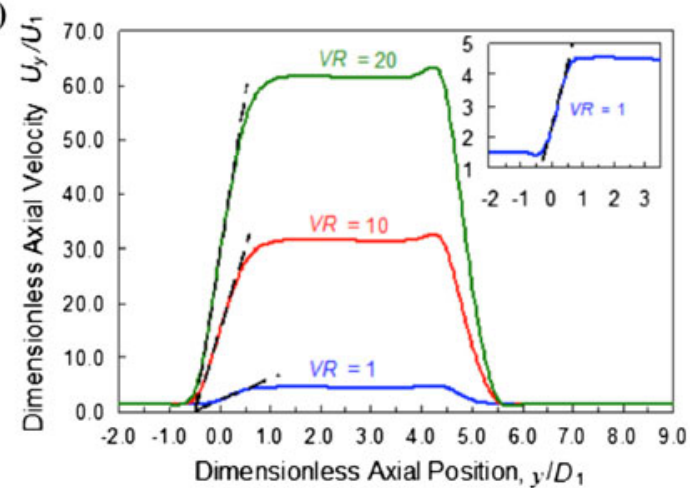

only one general device the user can analyze the extensional flow for a range of $\epsilon_{H}$. Obviously, things are more complex in practice, since the effect of the top and bottom walls has to be taken into consideration, and that inertia might not be negligible for large flow rates. However, this technique for generating extensional flows in microchannels has a great potential despite the lack of published experimental works up to date. This is, undoubtedly, an interesting and relevant area for future research.

Recently, Wang and James (2011) proposed an experimental technique to estimate the extensional viscosity of dilute polymer solutions as a function of the strain rate using flow in a lubricated, converging microchannel. This apparent extensional viscosity is calculated from the difference between the measured pressure drop and the calculated pressure drop that would occur only due to shear effects in the core flow. The microdevice used consists of a central channel conducting the core fluid, which is connected with two side streams containing the lubricating fluid. The fluids then flow through a hyperbolic contraction and an abrupt expansion, as shown in Fig. 17. The authors analyzed the effect of miscibility of the lubricating fluid, and they concluded that flow stability relies on using an immiscible lubricant, which is crucial for assessing fluid resistance to extensional deformation. This technique is also promising as a microfluidic extensional rheometer suitable for characterizing a wide range of weakly elastic fluids.

\begin{tabular}{|l|lll|}
\hline & Journal : Large 10404 & Dispatch : 23-7-2012 & Pages : $\mathbf{1 9}$ \\
Article No. : $\mathbf{1 0 2 8}$ & $\square_{\text {LE }}$ & $\square$ TYPESET \\
MS Code : & $\checkmark_{\text {CP }}$ & $\checkmark_{\text {DISK }}$ \\
\hline
\end{tabular}


Fig. 17 Schematic of the lubricated hyperbolic microchannel. The inset picture shows a viscous Newtonian fluid lubricated by water introduced through the lateral inlets. Reprinted with permission from Wang and James (2011), Copyright (2011), American Institute of Physics for the Society of Rheology

\subsection{Electrowetting-on-dielectric microfluidic actuators}

More than one century after the groundbreaking work in electrocapillarity by Lippmann (1875), who discovered that the capillary depression of mercury in contact with electrolyte solutions could be varied by changing the applied voltage between the mercury and the electrolyte (Mugele and Baret 2005), the "Electrowetting" effect was described by Beni and Hackwood (1981) with a practical application in the development of passive displays. In order to overcome the problem of electrolysis upon applying voltages beyond a few millivolts, Berge (1993) proposed to cover the metallic electrode with a thin insulate layer, which gave place to the concept of Electrowetting-on-dielectric (EWOD). Its application to microfluidics is based on the actuation of tiny amounts of liquids using the principle of modulating the interfacial tension between a liquid and an electrode coated with a dielectric layer. When the electric field is applied only to a portion of the droplet, an imbalance of interfacial tension is created, which forces the droplet to move (Pollack et al. 2010). Droplets are usually sandwiched between two parallel plates: the electrode array is located at the bottom plate, while the top surface is either a continuous ground plate or a passive top plate (Song et al. 2009). EWOD has become a widely used concept in various microfluidic operations including the actuation, formation, splitting, and mixing of droplets on smooth surfaces (Kumari and Garimella 2011).

The potential of using EWOD actuation in rheometry was demonstrated by Lin et al. (2007), who proposed a microviscometer based on electrowetting-on-dielectric, and Banpurkar et al. (2009), who used EWOD to determine the elastic moduli of gelled aqueous droplets by using a sessile

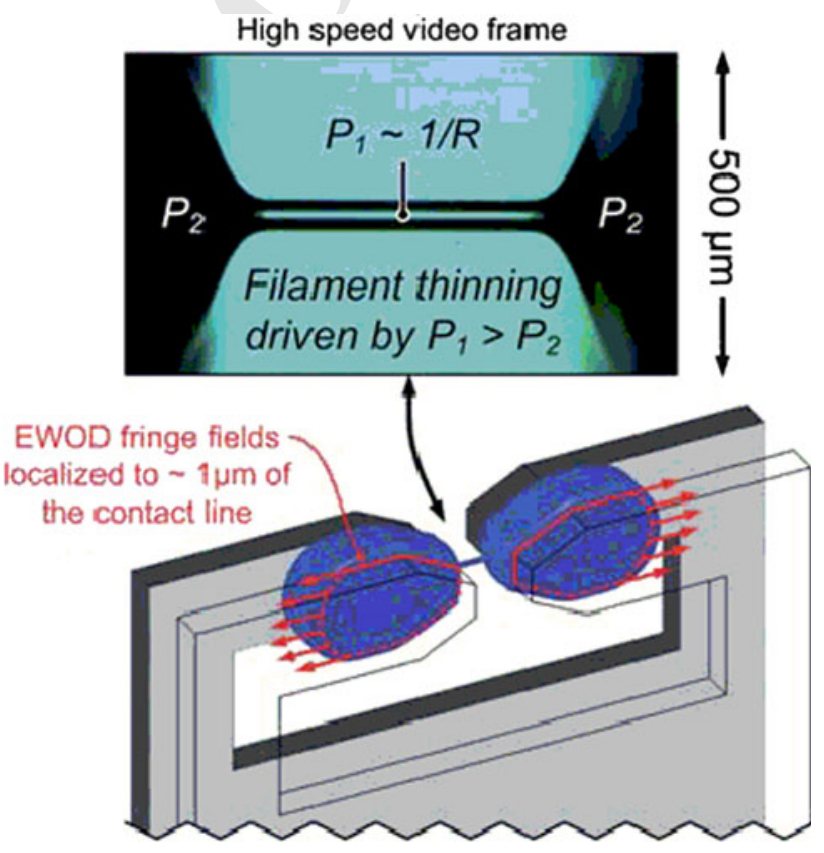

Fig. 18 Three-dimensional sketch of a loaded chip and close-up of the liquid bridge formed using EWOD activation. Reprinted with permission from Nelson et al. (2011), Copyright (2011), The Royal Society of Chemistry

droplet and relating liquid properties (e.g. elastic modulus) to the voltage-dependent measured contact angle. More recently, Nelson et al. $(2010,2011)$ went a step forward and proposed the equivalent of a miniaturized $\mathrm{CaBER}^{\mathrm{TM}}$ based on EWOD. Instead of miniaturizing the existing actuators, they took advantage of the favorable scaling of surface forces at the microscale and EWOD actuation to avoid using moving parts. Thus, depending on their electrical properties, the test samples are pulled by EWOD effects which stretch

\begin{tabular}{|l|lll|}
\hline & Journal : Large 10404 & Dispatch : 23-7-2012 & Pages : $\mathbf{1 9}$ \\
Article No. : $\mathbf{1 0 2 8}$ & $\square_{\mathrm{CP}}^{\mathrm{LE}}$ & $\square_{\text {TISESET }}^{\text {TYPESET }}$ \\
\hline
\end{tabular}


the droplet as shown in Fig. 18, similar to the way in which the $\mathrm{CaBER}^{\mathrm{TM}}$ uses linear actuators to impose a step strain extending the liquid bridge.

This EWOD extensional rheometer exhibits the following advantages:

- the undesired oscillations of the suspended fluid induced by inertia are minimized, as the test platform handles tiny sample volumes (Kojic et al. 2006),

- the apparatus is able to easily generate shear-free fluid filaments by either spontaneous capillary wetting or using EWOD actuation. In this scheme, the capillary breakup of a viscoelastic filament is driven by Laplace pressure, and opposed by internal shear and elasticity, without the influence of gravity or inertial-driven oscillations. Therefore, it is possible to measure complex fluids' properties using the known models resulting from a balance of these dominant forces (Nelson et al. 2010),

- the shape of the sample holding platform can be designed in order to facilitate the necking process and to ensure that the measurement point (i.e., the location of the minimum radius of the filament) remains fixed in space (Nelson et al. 2010), which is an advantage with regards to the design of the original $\mathrm{CaBER}^{\mathrm{TM}}$ system and

- the micro-machined chip can be easily fabricated and can be scaled down to handle sub-microliter volumes, making it especially useful for characterizing expensive materials and scarce biological fluids.

However, the instrument has also some limitations, such as:

- the applied voltages might influence the rheological properties of the fluid,

- the length of the initial filament is fixed for each chip, and may not be appropriate for all kinds of fluids and

- the pre-deformation history cannot be properly controlled.

\subsection{Surface acoustic wave-induced fluid jetting}

Tan et al. (2009) demonstrated experimentally that it is possible to generate a liquid jet ejecting up to $1-2 \mathrm{~cm}$
804

790

791

792

793

794

795

796

797

798

799

800

801

802

803

805

806
Fig. 19 a Set-up to generate the focused SAWs whose radiation into the drop placed on the substrate focal point induces a deformation into a coherent elongated jet as shown in b-d. The water-air interface reflects the acoustic radiation throughout the vertical fluid column as illustrated in d. Reprinted with permission from Tan et al. (2009). Copyright (2009) by the American Physical Society (a)
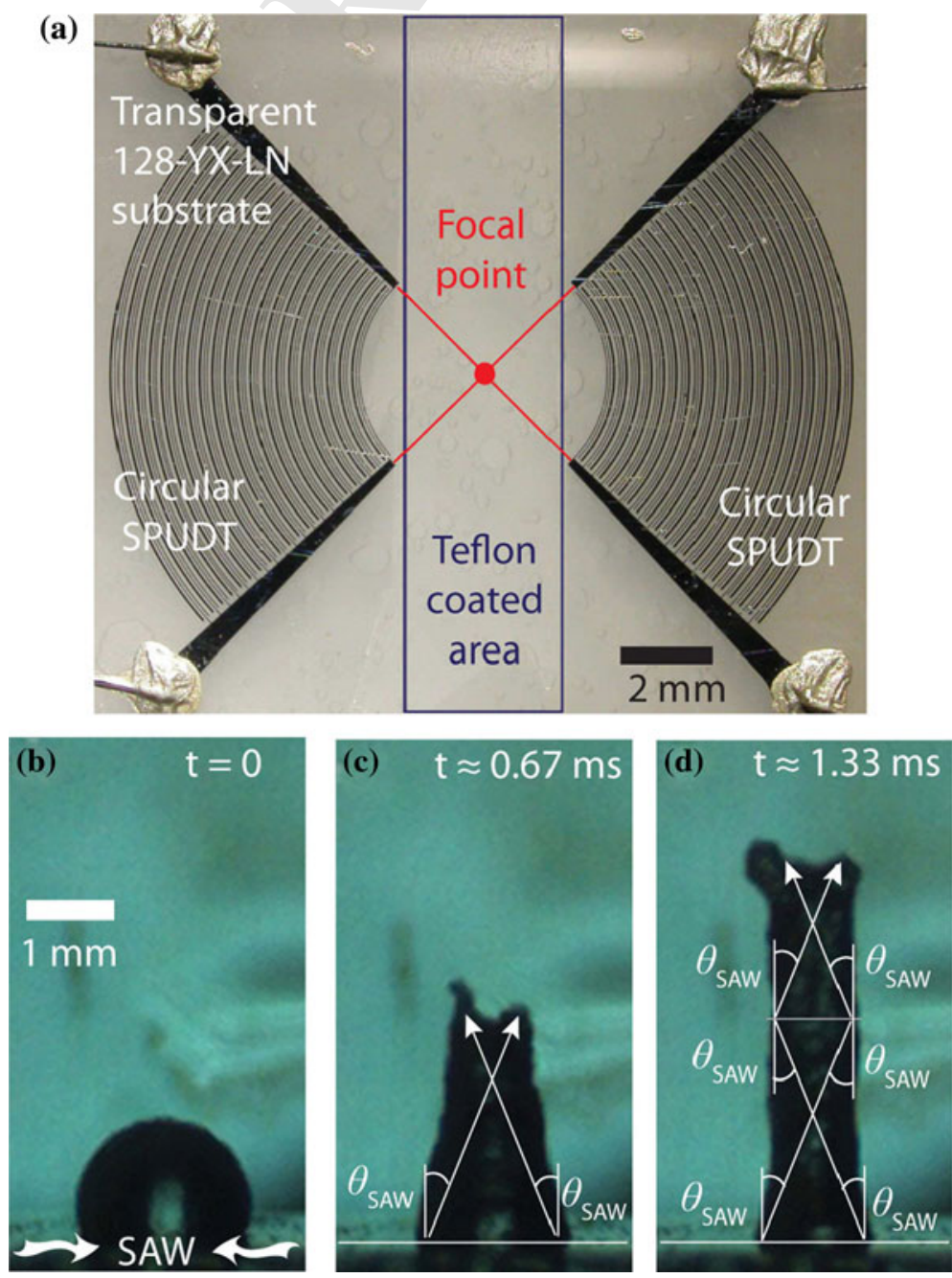

\begin{tabular}{|l|lll|}
\hline Journal : Large 10404 & Dispatch : 23-7-2012 & Pages : 19 \\
Article No. : $\mathbf{1 0 2 8}$ & $\square$ LE & $\square$ TYPESET \\
MS Code : & $\sim_{\mathrm{CP}}$ & $\checkmark$ DISK \\
\hline
\end{tabular}


Fig. 20 a Set-up for SAW jetting. b The solutions used by Bhattacharjee et al. (2011) are shown as symbols. The shaded region in the $\lambda-\eta_{0}$ parameter space is difficult to access in conventional $\mathrm{CaBER}^{\mathrm{TM}}$ experiments. c Jet formation from the droplet and bridge necking down under the influence of capillary forces acting at the interface. The numbers correspond to the elapsed time in milliseconds. Reprinted from Bhattacharjee et al. (2011), Copyright (2011), with permission from IOP Publishing Ltd
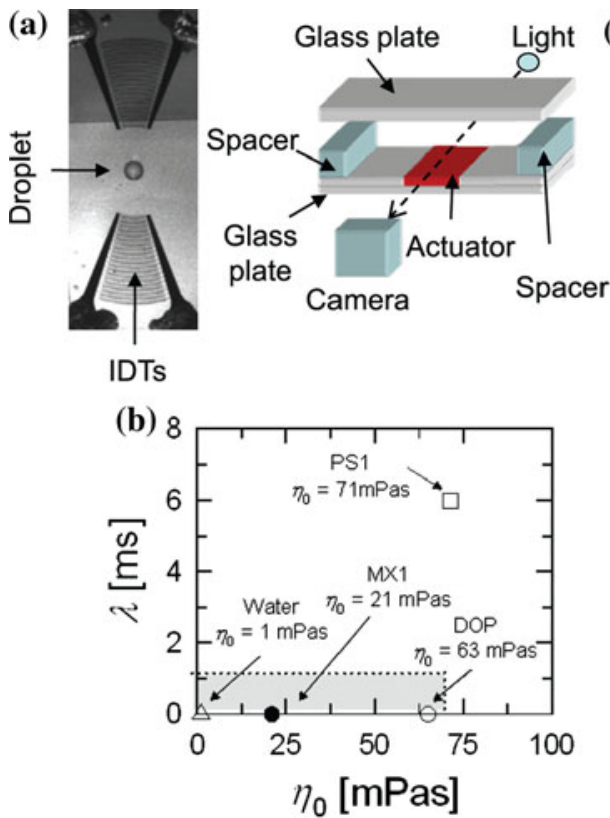

(c)
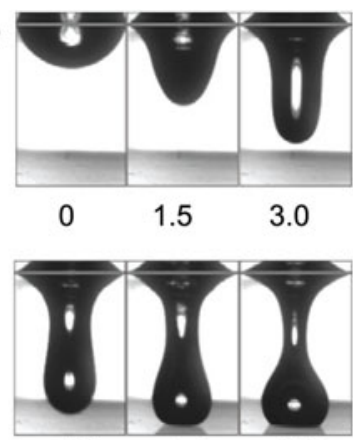

4.5

$6.0 \quad 7.5$

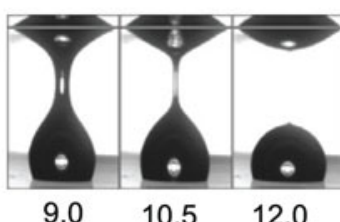

807

808

809

810

811

812

813

814

815

816

817

818

819

820

821

822

823

824

825

826

827

828

829

830

831

832

833

834

835

836

837

838

839 from the free surface of a sessile drop by concentrating the energy of surface acoustic waves (SAW) into the mentioned drop (cf. Fig. 19). Based on this phenomenon, Bhattacharjee et al. (2011) were able to investigate the extensional flow of low-viscosity fluids in capillary bridges formed by pulsed surface acoustic wave jetting. Focusing electrodes at the ends of a lithium niobate piezoelectric crystal provided a focused SAW into the drop placed on the substrate at the focal point, generating a deformation in the form of a coherent elongated jet (left panel of Fig. 20). Using this principle, a liquid bridge can be created when the resulting jet touches and attaches to the top end-plate. In the experiments of Bhattacharjee et al. (2011), the setup was inverted and the droplet jet moved downwards along the direction of gravity. Figure 20c shows the time evolution of the coherent jet formed from the droplet and creation of the liquid bridge. For rheometric measurements the start time is $t_{0}=7.5 \mathrm{~ms}$, the time at which the SAW actuation ends for the experiment illustrated in Fig. 20c. Subsequently, the bridge thins under the influence of capillary forces acting at the interface. The relaxation time for different fluids are shown in Fig. 20b, illustrating that reliable measurements of Newtonian and viscoelastic fluids can be obtained in the region where the conventional $\mathrm{CaBER}^{\mathrm{TM}}$ apparatus cannot be used (grey area in Fig. 20b) due to inertia-driven oscillations, with the added advantage of using a small amount of liquid $(\leq 5 \mu \mathrm{l})$. However, the major drawback of this technique lies on the complex combination of operating variables (aperture of the SAW interdigital transducer, contact angle of the fluid, amplitude of the induced SAW and alignment of the end-plates) that must be properly controlled to significantly enhance the reproducibility of the breakup time of liquid bridges. Without due care, the droplet can fail to jet and form a liquid bridge or even atomize.

\section{Perspectives}

In this review, we discuss recent advances in microfluidic techniques relevant for the development of an extensional rheometer-on-a-chip able to characterize the extensional properties of low viscosity elastic fluids. In recent years, microfluidics has evolved from being a promising platform for rheometry to becoming one of the most suitable approaches in the characterization of extensional properties of dilute polymer solutions at the moment. However, despite the great progresses, there is still much to be done in order to improve current techniques and, of course, there are also many unexplored approaches to be pursued. In designing and optimizing a microfluidic geometry it is desirable to combine experiments with numerical computations of the corresponding flow field in order to achieve an ideal flow field and systematically explore the sensitivity of the kinematics to changes in the geometry and the flow conditions. This is arguably the best approach to proceed in order to succeed in the quest of designing efficient microfluidic extensional rheometers with optimal performance.

Acknowledgments The authors would like to acknowledge Fundação para a Ciência e a Tecnologia (FCT), COMPETE and FEDER for financial support through projects PTDC/EME-MFE/099109/ 2008, PTDC/EME-MFE/114322/2009, PTDC/EQU-FTT/118716/ 2010 and the scholarship SFRH/BPD /69663/2010. The authors also thank Dr. Rob Poole (University of Liverpool) for helpful comments.
844

\begin{tabular}{|l|lll|}
\hline & Journal : Large 10404 & Dispatch : 23-7-2012 & Pages : 19 \\
Article No. : $\mathbf{1 0 2 8}$ & $\square$ LE & $\square$ TYPESET \\
MS Code : & $\boldsymbol{\sim}_{\mathrm{CP}}$ & $\checkmark$ DISK \\
\hline
\end{tabular}




\section{References}

Alves MA (2008) Design a cross-slot flow channel for extensional viscosity measurements. AIP Conf Proc 1027:240-242

Anna SL, McKinley GH (2008) Effect of a controlled pre-deformation history on extensional viscosity of dilute polymer solutions. Rheol Acta 47:841-859

Anna SL, Rogers C, McKinley GH (1999) On controlling the kinematics of a filament stretching rheometer using a real-time active control mechanism. J Non Newton Fluid Mech 87:307-335

Anna SL, McKinley GH, Nguyen DA, Sridhar T, Muller S, Huang J, James DF (2001) An interlaboratory comparison of measurements from filament-stretching rheometers using common test fluids. J Rheol 45(1):83-114

Ardekani AM, Sharma V, McKinley GH (2010) Dynamics of bead formation, filament thinning and breakup in weakly viscoelastic jets. J Fluid Mech 665:46-56

Arratia PE, Thomas CC, Diorio J, Gollub JP (2006) Elastic instabilities of polymer solutions in cross-channel flow. Phys Rev Lett 96:144502

Arratia PE, Gollub JP, Durian DJ (2008) Polymeric filament thinning and breakup in microchannels. Phys Rev E 77:036309

Babcock HP, Teixeira RE, Hur JS, Shaqfeh ESG (2003) Visualization of molecular fluctuations near the critical point of the coil-stretch transition in polymer elongation. Macromolecules 36:4544-4548

Balducci AG, Tang J, Doyle PS (2008) Electrophoretic stretching of dna molecules in cross-slot nanoslit channels. Macromolecules 41:9914-9918

Bandalusena HCH, Zimmerman WB, Rees JM (2009) Microfluidic rheometry of a polymer solution by micron resolution particle image velocimetry: a model validation study. Meas Sci Technol 20:115404

Banpurkar AG, Duits MHG, van den Ende D, Mugele F (2009) Electrowetting of complex fluids: perspectives for rheometry on chip. Langmuir 25:1245-1252

Bänsch E, Berg CP, Ohlhoff A (2004) Uniaxial extensional flows in liquid bridges. J Fluid Mech 521:353-379

Barnes HA, Hutton JF, Walters K (1993) An introduction to rheology. Rheology series, 3rd edn. Elsevier, The Netherlands

Bazilevsky A, Entov V, Rozhkov A (1990) Liquid filament microrheometer and some of its applications. In: Oliver DR (ed) Proceedings of the third European rheology conference. Elsevier, The Netherlands, pp 41-43

Becherer P, Morozov AN, van Saarloos W (2008) Scaling of singular structures in extensional flow of dilute polymer solutions. J Non Newton Fluid Mech 153:183-190

Beni G, Hackwood S (1981) Electro-wetting displays. Appl Phys Lett 38(4):207-209

Berge B (1993) Electrocapillarité et mouillage de films isolants par l'eau. Comptes rendus de l' Academie des sciences Seŕie 2 317(2):157-163

Bhattacharjee PK, McDonnell AG, Prabhakar R, Yeo LY, Friend J (2011) Extensional flow of low-viscosity fluids in capillary bridges formed by pulsed surface acoustic wave jetting. New J Phys 13:023005

Bird RB, Armstrong RC, Hassager O (1987) Dynamics of polymer liquids. Fluid mechanics, vol 1, 2nd edn. Wiley, USA

Campo-Deaño L, Clasen C (2010) The slow retraction method (SRM) for the determination of ultra-short relaxation times in capillary breakup extensional rheometry experiments. J Non Newton Fluid Mech 165:1688-1699

Campo-Deaño L, Galindo-Rosales FJ, Pinho FT, Alves MA, Oliveira MSN (2011) Flow of low viscosity boger fluids through a microfluidic hyperbolic contraction. J Non Newton Fluid Mech 166:1286-1296
Cubaud T, Mason TG (2009) High-viscosity fluids threads in weakly diffusive microfluidic systems. New J Phys 11:075029

Dontula P, Pasquali M, Scriven LE, Macosko CW (1997) Can extensional viscosity be measured with opposed-nozzle devices. Rheol Acta 36:429-448

Dukhin A, Zelenev A (2010) Rheology: shear, extensional, longitudinal. Sci Topics. http://www.scitopics.com/Rheology_shear_ extensional_longitudinal.html (accessed 20 June 2012)

Dylla-Spears R, Townsend JE, Jen-Jacobson L, Sohn LL, Muller SJ (2010) Single-molecule sequence detection via microfluidic planar extensional flow at a stagnation point. Lab Chip 10:1543-1549

Erni P, Varagnat M, Clasen C, Crest J, McKinley GH (2011) Microrheometry of sub-nanolitre biopolymer samples: nonnewtonian flow phenomena of carnivorous plant mucilage. Soft Matter 7:10889

Franck A (2011) The ARES-EVF: option for measuring extensional viscosity of polymer melts. http://www.tainstruments.com/pdf/ literature/APN002_V2_ARES_EVF_to_measure_elongation viscosity.pdf (accessed 20 June 2012)

Fuller GG, Cathey CA, Hubbard B, Zebrowski BE (1987) Extensional viscosity measurements for low-viscosity fluids. J Rheol 31:235-249

Funami T (2011) Next target for food hydrocolloid studies: texture design of foods using hydrocolloid technology. Food Hydrocolloids 25:1904-1914

Gaudet S, McKinley GH (1998) Extensional deformation of nonNewtonian liquid bridges. Comput Mech 21:461-476

Göttfert (2011) Elongational testing-rheotens and haul-off. http://www.goettfert.com/images/stories/downloads/produkte/ Rheotens_71-97_en.pdf (accessed 20 June 2012)

Guillot P, Panizza P, Salmon JP, Joanicot M, Colin A (2006) Viscosimeter on a microfluidic chip. Langmuir 22:6438-6445

Guillot P, Moulin T, Kotitz RMG, Dodge A, Joanicot M, Colin A, Bruneau CH, Colin T (2008) Towards a continuous microfluidic rheometer. Microfluid Nanofluid 5:619-630

Gupta RK, Sridhar T (1988) Rheological Measurements. In: Clegg D, Collyer AA (eds) Elsevier, The Netherlands

Haward SJ (2010) Buckling instabilities in dilute polymer solution elastic strands. Rheol Acta 49:1219-1225

Haward SJ, Odell JA, Berry M, Hall T (2011) Extensional rheology of human saliva. Rheol Acta 50:869-879

Haward SJ, Ober TJ, Oliveira MSN, Alves MA, McKinley GH (2012a) Extensional rheology and elastic instabilities of a wormlike micellar solution in a microfluidic cross-slot device. Soft Matter 8:536-555

Haward SJ, Oliveira MSN, Alves MA, McKinley GH (2012b) Optimized cross-slot flow geometry for microfluidic extensional rheometry. Phys Rev Lett (submitted)

Hermansky CG, Boger DV (1995) Opposing-jet viscometry of fluids with viscosity approaching that of water. J Non Newton Fluid Mech 56:1-14

Hsieh SS, Huang YC (2008) Passive mixing in micro-channels with geometric variations through $\mu \mathrm{PIV}$ and $\mu \mathrm{LIF}$ measurements. J Micromech Microeng 18:065017

Hudson SD, Phelan FR, Handler MD, Cabral JT, Migler KB, Amis EJ (2004) Microfluidic analog of the four-roll mill. Appl Phys Lett 85(2):335-337

Husny J, Cooper-White JJ (2006) The effect of elasticity on drop creation in T-shaped microchannels. J Non Newton Fluid Mech 137:121-136

Kojic N, Bico J, Clasen C, McKinley GH (2006) Ex vivo rheology of spider silk. J Exp Biol 209:4355-4362

Kumari N, Garimella SV (2011) Electrowetting-induced dewetting transitions on superhydrophobic surfaces. Langmuir 27:1034210346 
Lagnado RR, Leal LG (1990) Visualization of three-dimensional flow in a four-roll mill. Exp Fluids 9:25-32

Lee JS, Dylla-Spears R, Teclemariam NP, Muller SJ (2007) Microfluidic four-roll mill for all flow types. Appl Phys Lett 90:074103

Lee W, Walker LM, Anna SL (2011) Competition between viscoelasticity and surfactant dynamics in flow focusing microfluidics. Macromol Mater Eng 296:203-213

Lin YY, Lin CW, Yang LJ, Wang AB (2007) Micro-viscometer based on electrowetting on dielectric. Electrochim Acta 52:2876-2883

Link DR, Anna SL, Weitz DA, Stone HA (2004) Geometrically mediated breakup of drops in microfluidic devices. Phys Rev Lett 92(5):054503

Lippmann G (1875) Relations entre les phénomènes électriques et capillaires. Ann Chim Phys 5:494

Macosko CW (1994) Rheology: principles, measurements, and applications. Wiley, USA

Maia JM, Covas JA, Nóbrega JM, Dias TF, Alves FE (1999) Measuring uniaxial extensional viscosity using a modified rotational rheometer. J Non Newton Fluid Mech 80:183-197

Matta JE, Tytus RP (1990) Liquid stretching using a falling cylinder. J Non Newton Fluid Mech 35:215-229

McKinley GH (2005) Visco-elasto-capillary thinning and break-up of complex fluids. In: Binding DM, Walters K (eds) Rheology reviews. The British Society of Rheology

McKinley GH, Hall NR (2011a) Shear history extensional rheology experiment II (SHERE II). http://issresearchproject.grc.nasa.gov/ MSG/SHERE_II/ (accessed 20 June 2012)

McKinley GH, Hall NR (2011b) Shear history extensional rheology experiment (SHERE). http://issresearchproject.grc.nasa.gov/ MSG/SHERE/ (accessed 20 June 2012)

McKinley GH, Sridhar T (2002) Filament-stretching rheometry of complex fluids. Annu Rev Fluid Mech 34:375-415

McKinley GH, Tripathi A (2000) How to extract the Newtonian viscosity from capillary breakup measurements in a filament rheometer. J Rheol 44(3):653-671

McKinley GH, Brauner O, Yao M (2001) Kinematics of filament stretching in dilute and concentrated polymer solutions. Korea Austral J Rheol 13(1):29-35

Meissner J (1985a) Experimental aspects in polymer melt elongational rheometry. Chem Eng Commun 33:159-180

Meissner J (1985b) Rheometry of polymer melts. Annu Rev Fluid Mech 17:45-64

Mugele F, Baret JC (2005) Electrowetting: from basics to applications. J Phys Condens Matter 17:R705-R774

Münsted H (1979) New universal extensional rheometer for polymer melts. Measurements on a polystyrene sample. J Rheol 23(4):421-436

Nelson WC, Kavehpour HP, Kim CJ (2010) A micro extensional filament rheometer enabled by EWOD. In: IEEE 23rd international conference on micro electro mechanical systems (MEMS), pp 75-78

Nelson WC, Kavehpour HP, Kim CJ (2011) A miniature capillary breakup extensional rheometer by electrostatically assisted generation of liquid filaments. Lab Chip 11:2424-2431

Ng SL, Mun RP, Boger DV, James DF (1996) Extensional viscosity measurements of dilute polymer solutions of various polymers. J Non Newton Fluid Mech 65:291-298

Niedzwiedz K, Arnolds O, Willenbacher N, Brummer R (2009) How to characterize yield stress fluids with capillary breakup extensional rheometry (CaBER). Appl Rheol 19(4):41969

Niedzwiedz K, Buggisch H, Willenbacher N (2010) Extensional rheology of concentrated emulsions as probed by capillary breakup elongational rheometry (CaBER). Rheol Acta 49:1103-1116
Nijenhuis K, McKinley GH, Spiegelberg S, Barnes HA, Aksel N, Heymann L, Odell JA (2007) Springer handbook on experimental fluid mechanics, Chap 9. Non-Newtonian flows. Springer, Berlin

Odell JA, Carrington SA (2006) Extensional flow oscillatory rheometry. J Non Newton Fluid Mech 137:110-120

Oliveira MSN, McKinley GH (2005) Iterated stretching and multiple beads-on-a-string phenomena in dilute solutions of highly extensible flexible polymers. Phys Fluids 17:071704

Oliveira MSN, Yeh R, McKinley GH (2006) Iterated stretching, extensional rheology and formation of beads-on-a-string structures in polymer solutions. J Non Newton Fluid Mech 137:137-148

Oliveira MSN, Alves MA, Pinho FT, McKinley GH (2007a) Viscous flow through microfabricated hyperbolic contractions. Exp Fluids 43:437-451

Oliveira MSN, Oliveira PJ, Pinho FT, Alves MA (2007b) Effect of contraction ratio upon viscoelastic flow in contractions: the axisymmetric case. J Non Newton Fluid Mech 147:92-108

Oliveira MSN, Alves MA, Pinho FT (2008a) Extensional effects in viscoelastic fluid flow through a micro-scale double cross-slot. AIP Conf Proc 1027:982-984

Oliveira MSN, Rodd LE, McKinley GH, Alves MA (2008b) Simulations of extensional flow in microrheometric devices. Microfluid Nanofluid 5:809-826

Oliveira MSN, Pinho FT, Poole RJ, Oliveira PJ, Alves MA (2009) Purely-elastic flow asymmetries in flow focusing devices. J Non Newton Fluid Mech 160:31-39

Oliveira MSN, Alves MA, Pinho FT (2012) Transport and mixing in laminar flows: from microfluidics to oceanic currents, Chap 6. Microfluidic flows of viscoelastic fluids. Wiley, New York

Padmanabhan M (1995) Measurement of extensional viscosity of viscoelastic liquid foods. J Food Eng 25:311-327

Padmanabhan M, Bhattacharya M (1993) Planar extensional viscosity of corn meal dough. J Food Eng 18:389-411

Pathak JA, Hudson SD (2006) Rheo-optics of equilibrium polymer solutions: wormlike micelles in elongational flow in a microfluidic cross-slot. Macromolecules 39:8782-8792

Perkins TT, Smith DE, Chu S (1997) Single polymer dynamics in an elongation flow. Science 314:216-221

Petrie CJS (1997) Three-dimensional presentation of extensional flow data. J Non Newton Fluid Mech 70:205-218

Petrie CJS (2006) Extensional viscosity: a critical discussion. J Non Newton Fluid Mech 137:15-23

Phelan FR Jr, Hudson SD, Handler MD (2005) Fluid dynamics analysis of channel flow geometries for materials characterization in microfluidic devices. Rheol Acta 45:59-71

Pipe C, McKinley GH (2009) Microfluidic rheometry. Mech Res Commun 36:110-120

Pipe C, Majmudar TS, McKinley GH (2008) High shear rate viscometry. Rheol Acta 47:621-642

Pollack MG, Fair RB, Shenderov AD (2010) Electrowetting-based actuation of liquid droplets for microfluidic applications. Appl Phys Lett 77:1725-1727

Poole RJ, Alves MA, Oliveira PJ (2007) Purely elastic flow asymmetries. Phys Rev Lett 99:164503

Remmelgas J, Singh P, Leal LG (1999) Computational studies of nonlinear elastic dumbbell models of boger fluids in a cross-slot flow. J Non Newton Fluid Mech 88:31-61

Ríos S, Díaz J, Galindo A, Soto E, Calderas F, Mena B (2002) Instrumentation and start up of a new elongational rheometer with preshearing history. Rev Sci Instrum 73:3007-3011

Roche M, Kellay H, Stone HA (2011) Heterogeneity and the role of normal stresses during the extensional thinning of non-Brownian shear-thickening fluids. Phys Rev Lett 107:34503
1064

1065

1066

1067

1068

1069

1070

1071

1072

1073

1074

1075

1076

1077

1078

1079

1080

1081

1082

1083

1084

1085

1086

1087

1088

1089

1090

1091

1092

1093

1094

1095

1096

1097

1098

1099

1100

1101

1102

1103

1104

1105

1106

1107

1108

1109

1110

1111

1112

1113

1114

1115

1116

1117

1118

1119

1120

1121

1122

1123

1124

1125

1126

1127

1128

\begin{tabular}{|l|lll|}
\hline & Journal : Large 10404 & Dispatch : 23-7-2012 & Pages : 19 \\
Article No. : $\mathbf{1 0 2 8}$ & $\square$ LE & $\square$ TYPESET \\
MS Code : & $\mho_{\mathrm{CP}}$ & $\boldsymbol{V}_{\text {DISK }}$ \\
\hline
\end{tabular}


Rodd LE, Scott TP, Boger DV, Cooper-White JJ, McKinley GH (2005a) The inertio-elastic planar entry flow of low-viscosity elastic fluids in micro-fabricated geometries. J Non Newtonian Fluid Mech 129:1-22

Rodd LE, Scott TP, Cooper-White JJ, McKinley GH (2005b) Capillary break-up rheometry of low-viscosity elastic fluids. Appl Rheol 15:12-27

Rodd LE, Cooper-White JJ, Boger DV, McKinley GH (2007) The role of elasticity number in the entry flow of dilute polymer solutions in micro-fabricated contraction geometries. J Non Newtonian Fluid Mech 143:170-191

Rothstein JP (2008) Strong flows of viscoelastic wormlike micelle solutions. In: Binding DM, Walters K (eds) Rheology reviews. The British Society of Rheology

Rothstein JP, McKinley GH (1999) Extensional flow of a polystyrene boger fluid through a 4:1:4 axisymmetric contraction/expansion. J Non Newton Fluid Mech 86:61-88

Rothstein JP, McKinley GH (2001) The axisymmetric contractionexpansion: the role of extensional rheology on vortex growth dynamics and the enhanced pressure drop. J Non Newton Fluid Mech 98:33-63

Sattler R, Wagner C, Eggers J (2008) Blistering pattern and formation of nanofibers in capillary thinning of polymer solutions. Phys Rev Lett 100:164502

Schultz WW, Davis SH (1982) One-dimensional liquid fibers. J Rheol 26(4):331-345

Schweizer T (2000) The uniaxial elongational rheometer rme-six years of experience. Rheol Acta 39:428-443

Sentmanat M, Wang BN, McKinley GH (2005) Measuring the transient extensional rheology of polyethylene melts using the ser universal testing platform. J Rheol 49(3):585-606

Shaqfeh ESG (2005) The dynamics of single-molecule dna in flow. J Non Newton Fluid Mech 130:1-28

Song JH, Evans R, Lin YY, Hsu BN, Fair RB (2009) A scaling model for electrowetting-on-dielectric microfluidic actuators. Microfluid Nanofluid 7:75-89

Soulages J, Le Goupil F, Hostettler J, McKinley GH (2009a) An opposed-nozzle fixture for measuring the extensional properties of low viscosity liquids using a conventional controlled strain rheometer. In: Co A (ed) The Society of Rheology. 81st annual meeting program and abstracts, $\mathrm{p} 115$

Soulages J, Oliveira MSN, Sousa PC, Alves MA, McKinley GH (2009b) Investigating the stability of viscoelastic stagnation flows in t-shaped microchannels. J Non Newton Fluid Mech 163:9-24

Sousa PC, Coelho PM, Oliveira MSN, Alves MA (2011) Laminar flow in three-dimensional square-square expansion. J Non Newton Fluid Mech 166:1033-1048

Squires TM, Mason TG (2010) Fluid mechanics of microrheology. Annu Rev Fluid Mech 42:413-438

Squires TM, Quake SR (2005) Microfluidics: fluid physics at the nanoliter scale. Rev Mod Phys 77:977-1026

Sridhar T (2000) From rheometry to rheology. Korea Austral Rheol J $12(1): 39-53$

Tan MK, Friend JR, Yeo LY (2009) Interfacial jetting phenomena induced by focusing surface vibrations. Phys Rev Lett 103:024501

Tanner RI (1988) Pressure-hole errors-an alternative approach. J Non Newtonian Fluid Mech 28:309-318

Tanyeri M, Johnson-Chavarria EM, Schroeder CM (2010) Hydrodynamic trap for single particles and cells. Appl Phys Lett 96:224101

Tanyeri M, Ranka M, Sittipolkul N, Schroeder CM (2011) A microfluidic-based hydrodynamic trap: design and implementation. Lab Chip 11:1786-1794

Taylor GI (1934) The formation of emulsions in definable fields of flow. Proc Roy Soc Lond Ser A 146:501-523

Trouton FT (1906) On the coefficient of viscous traction and its relation to that of viscosity. Proc Roy Soc Lond 77:426-440

Wang J, James DF (2011) Lubricated extensional flow of viscoelastic fluid in a convergent microchannel. J Rheol 55:1103-1126

Whitesides GM (2006) The origins and future of microfluidics. Nature 42:368-370

Zheng R, Tanner RI, Fan XJ (2011) Injection molding: integration of theory and modeling methods. Springer, Berlin
1167

1168

1169

1170

1171

1172

1173

1174

1175

1176

1177

1178

1179

1180

1181

1182

1183

1184

1185

1186

1187

1188

1189

1190

1191

1192

1193

1194

1195

1196

1197

1198

1199

1200

1201

1202

1203

1204

\begin{tabular}{|l|lll|}
\hline & Journal : Large $\mathbf{1 0 4 0 4}$ & Dispatch : 23-7-2012 & Pages : $\mathbf{1 9}$ \\
Article No. : $\mathbf{1 0 2 8}$ & $\square$ LE & $\square$ TYPESET \\
MS Code : & $\sim_{\text {CP }}$ & $\checkmark$ DISK \\
\hline
\end{tabular}

